\title{
Transfer Zone of Prestressed CFRP Reinforcement Applied According to NSM Technique for Strengthening of RC Structures
}

\author{
Mohammadali Rezazadeh, ${ }^{1}$ Joaquim Barros, ${ }^{2}$
}

\begin{abstract}
This study presents an experimental program to assess the tensile strain distribution along prestressed carbon fiber reinforced polymer (CFRP) reinforcement flexurally applied on the tensile surface of RC beams according to near surface mounted (NSM) technique. Moreover, the current study aims to propose an analytical formulation, with a design framework, for the prediction of distribution of CFRP tensile strain and bond shear stress and, additionally, the prestress transfer length. After demonstration the good predictive performance of the proposed analytical approach, parametric studies were carried out to analytically evaluate the influence of the main material properties, and CFRP and groove cross section on the distribution of the CFRP tensile strain and bond shear stress, and on the prestress transfer length. The proposed analytical approach can also predict the evolution of the prestress transfer length during the curing time of the adhesive by considering the variation of its elasticity modulus during this period.
\end{abstract}

Keywords: A. Carbon fiber; A. Laminates; B. Stress transfer; C. Analytical modeling.

\footnotetext{
${ }^{1}$ ISISE, PhD student of the Structural Division of the Dep. of Civil Engineering, University of Minho, 4800-058 Guimarães, Portugal.rzh.moh@gmail.com

${ }^{2}$ ISISE, Full Professor of the Structural Division of the Dep. of Civil Engineering, University of Minho, 4800-058 Guimarães, Portugal. barros@ civil.uminho.pt
} 


\section{Introduction}

Carbon fiber reinforced polymer (CFRP) reinforcement applied according to the near surface mounted (NSM) technique has provided higher strengthening effectiveness than the externally bonded reinforcing (EBR) technique for the flexural and shear strengthening of RC structures due to the higher confinement to the CFRP composite material provided by the surrounding concrete in the NSM technique [1-3]. Although the ultimate flexural capacity of RC structures can be increased significantly by using FRP reinforcement, its efficiency for the flexural strengthening may be limited by the occurrence of premature failure modes, such as: concrete cover delamination, and debonding of FRP from the concrete substrate [4-6]. However, an anchorage device can be used at the extremity zones of FRP strengthened structure in order to provide a higher resistance to susceptibility of these premature failure modes [7]. On the other hand, proposing simplified design formulations for the prediction of these premature failure modes of FRP strengthened beams is still an important issue that needs to be addressed, since engineers with limited exposure to FRP design need a guidance to design this type of strengthened structures by hand calculation without any programming help $[5-6,8]$.

Applying a certain prestress level to the NSM CFRP reinforcement can mobilize the strengthening potentialities of high tensile strength of this composite material $[9,10]$. The prestressed CFRPs provide several benefits like the decrease of the crack width and cracked zone length for serviceability limit state (SLS) conditions, higher load carrying capacity in terms of concrete cracking, steel yield initiation and for the deflection levels corresponding to SLS. These benefits are as higher as larger is the prestress level applied to the NSM CFRP reinforcement, as long as the initial prestress strain is limited in order to do not promote a premature failure of the CFRP [11-13]. In spite of these benefits, the experimental research has shown that the deflection capacity at failure of RC beams flexurally strengthened with prestressed CFRPs decreases with the increase of the prestress level $[11,13]$. To improve the ultimate deflection capacity of NSM CFRP strengthened RC beams, partially bonded system (similar to fully bonded system except an unbonded portion of NSM CFRP length at mid-span) was applied by Choi et al. (2011) [14]. Moreover, in this regard, in order to provide a good balance in terms of load carrying and ultimate deflection capacity, Rezazadeh and Barros

(2014) proposed a NSM hybrid strengthening technique combining non-prestressed and prestressed CFRP reinforcements in the same application [15]. 
After the total release of prestress force, an instantaneous prestress loss is occurred in the CFRP reinforcement due to the initial negative camber [16]. The residual prestress force is transferred from CFRP reinforcement to concrete over a length in both extremities of the CFRP through interfacial bond between CFRP-epoxy adhesive and concrete-epoxy adhesive connections. This length is known as transmission length, or transfer length, which is one of the critical aspect that should be taken into account for designing the prestressed RC beams [17], but a closed form solution for its analytical prediction still does not exist.

Hence, the current study aims to first assess experimentally the tensile strain distribution along the prestressed NSM CFRP reinforcement flexurally applied on the tensile surface of the RC beams and then, propose an analytical formulation, with a design framework, for the prediction of prestress transfer length. The analytical approach is developed by considering the influence of the effective parameters on the prestress transfer length, like elasticity modulus of concrete, CFRP, and epoxy adhesive, and their corresponding thickness. Besides, the proposed approach offers a method to identify the transfer length using tensile strain distribution along the CFRP length. Moreover, the analytical equations are proposed to predict the distribution of the CFRP tensile strain and bond shear stress along the CFRP bonded length when the prestress force is released.

After demonstration the good predictive performance of the proposed analytical approach, a series of parametric studies was carried out to analytically evaluate the influence on the prestress transfer length of the different material properties, CFRP and groove cross section, and hardening of epoxy adhesive during its curing time. Subsequently, a formula is proposed to predict the evolution of the prestress transfer length during the curing time of epoxy adhesive.

\section{Experimental Program}

\subsection{Specimens}

The experimental program reported in this paper was composed of four rectangular cross-section RC beams flexurally strengthened with a CFRP laminate prestressed at 15\%,20\%,30\%, and $40 \%$ of its nominal tensile strength, by adopting the NSM technique. The geometry, steel and CFRP reinforcement details of the strengthened beams are schematically represented in Figure 1 (dimensions are in $\mathrm{mm}$ ). 
For the flexural strengthening of the RC beams according to NSM technique, a CFRP laminate of $1.4 \times 20 \mathrm{~mm}^{2}$ cross sectional area was installed into a groove of $6 \times 24 \mathrm{~mm}^{2}$ cross section pre-executed on the concrete cover along the total beam length (Figure 1b). The CFRP laminate was bonded to the surrounding concrete using epoxy adhesive (with the trademark of $S \& P$ Resin 220 epoxy adhesive), and its extremities become at $50 \mathrm{~mm}$ before the supports in order to simulate a real strengthening application for the NSM technique (more details about the real application can be found elsewhere [13]). To monitor the distribution of tensile strains, and assess the short-term prestress losses in the CFRP reinforcement after the release of the prestress force, eight strain gauges were installed on the laminate, placed at the distances from the extremities of the CFRP bonded length indicated in Figure 1a (SG 1-8).

\subsection{Prestressing setup and procedure}

The setup used to apply prestress force to the CFRP reinforcement, in the current experimental program, was designed by taking advantage of an existing high stiff reaction steel frame in the laboratory of Minho University (as shown in Figure 2). The applied prestress level was controlled by monitoring the average strain values of the strain gauges installed on the prestressed CFRP laminate (represented in Figure 1a), by considering the material properties reported by manufacturer (elasticity modulus of $150 \mathrm{GPa}$ and nominal tensile strength of $2000 \mathrm{MPa}$ ).

Applying and releasing of the prestress force was done at the sliding extremity of the prestressing setup using a hollow hydraulic cylinder of $200 \mathrm{kN}$ maximum capacity, to which is connected a through-hole load cell of same capacity to control release rate of the prestress force. The NSM prestressing procedure adopted for the current experimental program consists of the following steps: 1) opening a groove on the concrete cover of the beam's tensile surface using a diamond cutter; 2) cleaning the groove using a compressed air; 3) placing the laminate into the center position of the groove, and then applying the prestress force to the CFRP reinforcement; 4) filling the groove with epoxy adhesive; 5) releasing the prestress force after epoxy curing time. In fact, in case of applying prestressed CFRPs according to NSM technique, this procedure has a difficulty in terms of covering the CFRP reinforcement with epoxy adhesive due to the thin thickness of groove, causing an uncertainty to guarantee a completely covered CFRP.

To ensure a simultaneous release of the prestress force in both extremities of the bonded CFRP laminate, two steel rollers were placed under the beam, and additionally one electrical strain gauge was installed on the CFRP laminate 
at the fixed extremity to monitor the release rate of the prestress force at this extremity (as shown in Figure 2). The prestress force was totally removed after the recommended curing time for the epoxy adhesive ( $72 \mathrm{~h}$ at room temperature) adopting a relatively low rate of $0.3 \mathrm{kN} / \mathrm{min}$ to avoid damage in the CFRP-adhesive-concrete connections. A more detailed description of the prestressing setup used for this experimental program designed for laboratory conditions can be found elsewhere [13], where a prestressing system for applying on real conditions prestressed NSM CFRP laminate for the flexural strengthening is also introduced.

\subsection{Material properties}

The average values of the main properties for concrete, steel bars, CFRP laminate, and epoxy adhesive are indicated in Table 1, where the average compressive strength and Young's modulus of the concrete were evaluated from uniaxial compression tests on cylinders of $150 \mathrm{~mm}$ diameter and $300 \mathrm{~mm}$ height according to the recommendations of [18] at the age of the prestress releasing (153 days). The average values of the main properties of the steel bars ( 6 and $10 \mathrm{~mm})$ in terms of the stress at steel yield initiation, tensile strength, and elasticity modulus were obtained by executing uniaxial tensile tests according to [19]. Moreover, the tensile strength and elasticity modulus of the used CFRP laminate were characterized by uniaxial tensile tests considering the recommendations of [20]. Finally, after curing time of epoxy adhesive (3 days), the tensile strength and elasticity modulus of the epoxy adhesive were determined according to the recommendations of [21].

\section{Experimental Results}

\subsection{Release of the prestress force}

To evaluate a simultaneous release of the prestress force in both extremities of the bonded CFRP laminate, a comparison is represented in Figure 3a of the 40\% prestress force versus time recorded at the sliding extremity using the through-hole load cell, and at the fixed extremity using the installed strain gauge outside the bonded length of the CFRP reinforcement (shown in Figure 2). This figure evidences that the decrease of the prestress force at the fixed extremity occurred immediately after removing the corresponding force at the sliding extremity resulting in a simultaneous release of the prestress force in both extremities of the strengthened beam. 


\subsection{Distribution of CFRP tensile strain}

The relationship between the normalized tensile strains in the CFRP laminate after the total release of the prestress force and the distance from the end of the CFRP length bonded to the surrounding concrete is depicted in Figure $3 \mathrm{~b}$ for all the prestressed beams. The normalized strain means that the registered CFRP tensile strain is divided by the corresponding initial prestrain applied to the laminate $\left(\varepsilon_{f p}\right)$. This figure shows that the distribution of the tensile strain in the extremity region of the CFRP bonded length varies from zero (at its end section) to the effective tensile strain (

$\varepsilon_{e f}^{(c i)}$, a concept to be treated in section 4.2) and then, reaches a plateau along the CFRP length up to the mid-span of the beam. Furthermore, this figure evidences an insignificant influence of the prestress level on the transmission zone of the prestressed CFRP. Hence, in Figure 3b, the best fit curve for the distribution of the CFRP tensile strain is represented by considering the values of the normalized strains for all the tested beams, regardless the applied prestress level.

\subsection{Bond shear stress}

After the release of the prestress force, the variation of the tensile strain in the extremity regions of the CFRP bonded laminate (transmission zones) imposes a shear stress field on the CFRP-adhesive-concrete bonds. In fact, this bond shear stress, $\tau$, was determined using the evolution of the CFRP tensile strain considering the principles of static equilibrium along the CFRP bonded length, as it will be detailed in section 4.2. The relationship between the bond shear stress and distance from the end of CFRP bonded length is represented in Figure 4 for all the prestressed strengthened beams after the release of the prestress force. According to this figure, the bond shear stress increases with the level of the prestress force applied to the CFRP laminate. The bond shear stress decreases exponentially from the end of the CFRP bonded length, and becomes null at the end of the transmission zone (of about $150 \mathrm{~mm}$ ).

\section{Analytical approach}


Malek et al. (1998) proposed a combined shear-bending analytical model for the RC beams strengthened with EBR FRP plate to predict interfacial debonding failure at the end of the plate bonded length (cut-off point) [22]. This proposed model was modified by Hassan and Rizkalla (2003) to account for the double bonded area of FRP strips flexurally applied according to NSM technique [23]. According to this modification, debonding of NSM strips is assumed to occur as a result of high shear stress concentration at FRP cut-off point.

In the current study, the model proposed by Hassan and Rizkalla (2003) is modified to analytically predict the tensile strain distribution and bond shear stress along the NSM CFRP bonded length immediately after the release of the prestress force. The model takes into account the strain profile of the beam's cross section due to the negative camber created after the release of the prestress force (using the model proposed by Rezazadeh et al. (2014) [24]), as an initial condition (designated by superscript symbol of (ci)) for the strains in the constituent materials.

\subsection{Assumptions}

The following assumptions were adopted in the proposed analytical model:

- Linear elastic and isotropic behavior is used for concrete, epoxy adhesive, CFRP and steel reinforcement;

- $\quad$ There is no slip between steel and CFRP reinforcements with surrounding concrete;

- Strain in the longitudinal steel bars, CFRP reinforcement and concrete is directly proportional to their distance from the neutral axis of the cross section of the RC element.

\subsection{Analytical approach description}

The static equilibrium of an infinitesimal portion $(d x)$ of the strengthened RC beam after the release of the prestress force (at the level of section A-A shown in Figure 5), results in Eq. (1) to determine the bond shear stress ( $\tau$ ) along a length of $d x$ using the variation of the tensile stress in the CFRP reinforcement $\left(d \sigma_{f}\right)$ and its thickness $\left(a_{f}\right)$.

$$
\tau=\frac{a_{f}}{2} \cdot \frac{d \sigma_{f}}{d x}
$$


According to Figure 5, tensile stress in the CFRP reinforcement is transferred to the concrete surfaces mainly through shear stresses $(\tau)$ in the adhesive layers assuming linear elastic behavior for the adhesive and no-slip conditions for the interfacial connections. In other words, the tensile stress in the CFRP reinforcement is in equilibrium with shear stresses in both adhesive layers and a very thin layer of concrete substrate adjacent to the adhesive [25, 26]. Therefore, an effective bond stiffness $\left(k_{e}=G_{e} / t_{e}\right.$, where $G_{e}$ and $t_{e}$ are the effective shear modulus and its thickness, respectively) can be defined to simulate the bond shear stiffness of these materials surrounding the CFRP reinforcement (adhesive and thin concrete layers) applied according to the NSM technique (Figures 5 and 6a) [25]:

$$
k_{e}=\frac{G_{e}}{t_{e}}=\frac{k_{a} \cdot k_{c}}{k_{a}+k_{c}}
$$

where $k_{a}=G_{a} / t_{a}$ is the shear stiffness of adhesive layer $\left(G_{a}\right.$ and $t_{a}$ are the shear modulus and the thickness of adhesive, respectively), and $k_{c}=G_{c} / t_{c}$ is the shear stiffness of the thin layer of concrete adjacent to the adhesive layer ( $G_{c}$ and $t_{c}$ are the shear modulus and the thickness of concrete layer, respectively).

Assuming isotropic linear elastic behavior for concrete and epoxy adhesive, $G_{c}$ and $G_{a}$ can be derived using the modulus of elasticity of concrete $\left(E_{c}\right)$ and adhesive $\left(E_{a}\right)$, respectively:

$$
G_{c}=\frac{E_{c}}{2\left(1+v_{c}\right)}, G_{a}=\frac{E_{a}}{2\left(1+v_{a}\right)}
$$

where $v_{c}$ and $v_{a}$ are the Poisson's ratio of concrete and adhesive, respectively. Moreover, $t_{a}$ and $t_{c}$ are the thickness of the adhesive layer and a thin layer of concrete that is influenced by the shear stress exerting by the CFRP. For EBRFRP strengthened beams, $t_{c}$ is typically adopted as 2.5-3 times the maximum aggregate size, or about 40-50 mm [25, 27]. However, for FRP strengthened beams according to NSM technique, the following equation is proposed to determine $t_{c}$ (Figure 6b):

$$
t_{c}=\min \left(t_{c 1}, t_{c 2}, t_{c 3}\right)=\min \left(s_{f}^{\prime}, \frac{s_{f}}{2}, \frac{b_{g}}{2 \tan \left(30^{\circ}\right)}\right)
$$


where $s_{f}$ is the distance between two adjacent CFRPs, $s_{f}^{\prime}$ is the distance between the lateral face of the beam's cross section and the nearest CFRP (this assumption is inspired on the work of Rezazadeh et al. (2014) [24]). The last condition of Eq. (4) aims to consider the possibility of occurring a failure mode for NSM FRP system according to concrete fracture propagation through inclined planes with an angle of approximately $30^{\circ}$ with the beam's tensile surface $\left(t_{c 3}=b_{g} / 2 \tan \left(30^{\circ}\right)\right.$, where $b_{g}$ is the groove's depth), as represented in Figure $6 \mathrm{~b}$, which was inspired on the work of De Lorenzis and Teng (2007) [28].

Therefore, by assuming linear elastic behavior for the constituent materials, bond shear stress can be obtained by the following equation:

$$
\tau=G_{e} \cdot \gamma \rightarrow \gamma=\frac{d u}{d z}+\frac{d w}{d x}
$$

where $\gamma$ is the shear strain, $u$ and $w$ are the longitudinal and transversal displacements of $t_{e}$ (Figure 5).

Differentiating Eqs. (1) and (5) with respect to $x$, results in:

$$
\frac{d^{2} \sigma_{f}}{d x^{2}}=\frac{2 \cdot G_{e}}{a_{f}}\left(\frac{d^{2} u}{d x . d z}+\frac{d^{2} w}{d x^{2}}\right)
$$

where $d^{2} w / d x^{2}$ can be neglected due to symmetry conditions, and $d^{2} u / d x . d z$ can be expressed as:

$$
\frac{d^{2} u}{d x . d z}=\frac{d}{d z}\left(\frac{d u}{d x}\right)=\frac{d}{d z}\left(\frac{d u_{c}}{d x}-\frac{d u_{f}}{d x}\right)=\frac{1}{t_{e}}\left(\varepsilon_{c}-\varepsilon_{l s f}\right)
$$

where $u_{c}$ and $u_{f}$ are the longitudinal displacement of concrete and CFRP reinforcement, respectively, at the level of section A-A (Figure 5). $\varepsilon_{c}$ is the compressive strain in concrete at the level of NSM CFRP reinforcement (section AA in Figure 5). Besides, $\varepsilon_{l s f}$ is the reduction of tensile strain in the CFRP reinforcement due to the short-term prestrain $\operatorname{loss}\left(\varepsilon_{l f}^{(c i)}\right)$ and its shortening effect after the prestress releasing that can be obtained by $\varepsilon_{l s f}=\varepsilon_{f p}-\varepsilon_{f}$ noting that $\varepsilon_{f p}$ and $\varepsilon_{f}$ are applied prestrain and tensile strain in the CFRP, respectively [29]. 
In fact, when the prestress force $\left(F_{p r e}\right)$ is released, an initial negative camber (upward deflection) is obtained due to the eccentricity $(e)$ of this prestress force in relation to the centroidal axis of the cross section ( $\left.y_{i}\right)($ Figure 7) [24]. This negative camber causes a compressive strain at the section A-A of concrete, which is equal to the short-term prestrain loss $\left(\varepsilon_{c}=\varepsilon_{l f}^{(c i)}\right)$ in the CFRP reinforcement assuming proportionality of the strain distribution along the cross section, as represented in Figure 7 [24]. This short-term prestrain loss and effective tensile strain $\left(\varepsilon_{e f}^{(c i)}\right)$ in the CFRP reinforcement immediately after total release of the prestress force are determined from the following equations:

$$
\varepsilon_{c}=\varepsilon_{l f}^{(c i)}=\frac{\varepsilon_{c c}^{(c i)} \cdot\left(d_{f}-c^{(c i)}\right)}{c^{(c i)}} \rightarrow \varepsilon_{e f}^{(c i)}=\varepsilon_{f p}-\varepsilon_{l f}^{(c i)}
$$

where $d_{f}$ is the internal arm of CFRP, $\varepsilon_{c c}^{(c i)}$ and $c^{(c i)}$ are the tensile strain at the concrete top fiber and neutral axis depth from the concrete top fiber after the release of the prestress force, whose equations are provided in Appendix A. It should be noted that the preloading effects due to the load conditions existing in the structure to be strengthened before installation of FRP reinforcement are considered as an initial strain profile of the cross section to obtain the tensile strain at the concrete top fiber $\left(\varepsilon_{c c}^{(c i)}\right)$ and neutral axis depth $\left(c^{(c i)}\right)$, since this allows a more accurate estimation of the tensile strain in the FRP reinforcement after strengthening process (see Appendix A).

Using Eqs. (2) and (7-8) in Eq. (6), results in:

$$
\frac{d^{2} \sigma_{f}}{d x^{2}}-\frac{2 \cdot G_{e}}{t_{e} \cdot a_{f} \cdot E_{f}} \sigma_{f}=-\frac{2 \cdot G_{e}}{t_{e} \cdot a_{f}}\left(\varepsilon_{f p}-\varepsilon_{l f}\right) \rightarrow \frac{d^{2} \sigma_{f}}{d x^{2}}-\frac{2 \cdot k_{e}}{a_{f} \cdot E_{f}} \sigma_{f}=-\frac{2 \cdot k_{e}}{a_{f}}\left(\varepsilon_{e f}^{(c i)}\right)
$$

By rewriting Eq. (9):

$$
\frac{d^{2} \sigma_{f}}{d x^{2}}-B^{2} \cdot \sigma_{f}=-B^{2} \cdot E_{f} \cdot \varepsilon_{e f}^{(c i)} \rightarrow B^{2}=\frac{2 k_{e}}{a_{f} \cdot E_{f}}
$$

where $B$ is a stiffness parameter.

The solution for Eq. (10) can be expressed as:

$$
\sigma_{f}(x)=C_{1} e^{B x}+C_{2} e^{-B x}+E_{f} \cdot \varepsilon_{e f}^{(\mathrm{ci})}
$$


The bond shear stress $(\tau$ ) can also be derived considering Eq. (1), as follows:

$$
\tau(x)=\frac{a_{f}}{2}\left(B \cdot C_{1} e^{B x}-B \cdot C_{2} e^{-B x}\right)
$$

The following boundary conditions can be adopted to determine the constants $C_{1}$ and $C_{2}$ :

$$
\begin{aligned}
& \sigma_{f}=0 \text { at } x=0 \\
& \tau=0 \quad \text { at } \quad x=L_{b} / 2
\end{aligned}
$$

where $L_{b}$ is the CFRP bonded length (Figure 5). Considering the introduced boundary conditions, the constants $C_{1}$ and $C_{2}$ can be expressed by:

$$
\begin{gathered}
C_{1}=\frac{-E_{f} \cdot \varepsilon_{e f}^{(c i)}}{\left(1+e^{B L_{b}}\right)} \\
C_{2}=\frac{-E_{f} \cdot \varepsilon_{e f}^{(c i)} \cdot e^{B L_{b}}}{\left(1+e^{B L_{b}}\right)}
\end{gathered}
$$

A parametric study of the variables in Eqs. (14) and (15) evidenced that $e^{B L_{b}}$ is always a very large number for the practical values of $B$ and $L_{b}$. Hence, $C_{2}$ can be simplified to $C_{2}=-E_{f} \cdot \varepsilon_{e f}^{(c i)}$ and $C_{1}$ can be ignored. Accordingly, Eqs. (11) and (12) can be rewritten as:

$$
\begin{gathered}
\sigma_{f}(x)=E_{f} \cdot \varepsilon_{e f}^{(\mathrm{ci})}\left(1-e^{-B x}\right) \\
\tau(x)=\frac{a_{f} \cdot E_{f} \cdot B \cdot \varepsilon_{e f}^{(c i)} \cdot e^{-B x}}{2}
\end{gathered}
$$

It should be noted that in the case of a round CFRP bar, for using the proposed analytical model, its cross section is converted to an equivalent square cross sectional area.

\subsection{Prestress transfer length}


When the prestress force is removed at both extremities of CFRP reinforcement after hardened stage of the epoxy, this force is transferred gradually from the CFRP to the surrounding concrete through a transmission zone at the extremity of the CFRP bonded length. In other words, the prestress force starts from zero at the end section of the CFRP bonded length and continues increasing along the transmission zone (known as prestress transfer length) and becomes constant beyond this zone. Moreover, variation of the prestress force in the CFRP along the transfer length causes a shear stress in the CFRP-adhesive-concrete bonds.

Russell and Burns (1993) proposed a method to determine transfer length for the prestressed steel strands using the tensile strain distribution along the prestressed element [30]. This method is known as 95\% Average Maximum Strain (95\%AMS) method and comprises the following steps (Figure 8a):

1. Plotting the tensile strain distribution along the prestressed element;

2. Determining the average maximum strain by computing the average strain values within the plateau zone of strain distribution after the release of the prestress force;

3. Considering a horizontal line corresponding to $95 \%$ of the average maximum strain;

4. Transfer length is determined by the intersection of the $95 \%$ line with the strain distribution plot.

In the current study, another method is also proposed to determine the prestress transfer length using an idealized trapezoid plot of the normalized tensile strain distribution along the FRP bonded length (designated as ITM method). According to this method, prestress transfer length $\left(T L_{(I T M)}\right)$ starts from the end section of FRP bonded length up to the beginning of plateau zone (see Figure $8 \mathrm{a}$ ). The dimensions of the idealized trapezoid plot are obtained assuming a height equal to $\varepsilon_{e f}^{(c i)} / \varepsilon_{f p}$ and an area equal to the area under the normalized CFRP tensile strain curve obtained by $\int\left(\sigma_{f}(x) /\left(E_{f} \cdot \varepsilon_{f p}\right)\right) d(x)$, as represented in Figure 8a. Hence:

$$
\int_{0}^{L_{b} / 2} \frac{\sigma_{f}(x)}{E_{f} \cdot \varepsilon_{f p}} d(x)=\left(\frac{\left(L_{b} / 2\right)+\left(\left(L_{b} / 2\right)-T L_{(I T M)}\right)}{2}\right) \cdot\left(\frac{\varepsilon_{e f}^{(c i)}}{\varepsilon_{f p}}\right)
$$

Rewriting Eq. (18) using Eq. (16) results in:

$$
\int_{0}^{L_{b} / 2} \frac{E_{f} \cdot \varepsilon_{e f}^{(\mathrm{ci})}\left(1-e^{-B x}\right)}{E_{f} \cdot \varepsilon_{f p}} d(x)=\left(\frac{\varepsilon_{e f}^{(c i)}}{\varepsilon_{f p}}\right) \cdot\left[x+\frac{e^{-B x}}{B}\right]_{0}^{L_{b} / 2}=\left(\frac{L_{b}-T L_{(I T M)}}{2}\right) \cdot\left(\frac{\varepsilon_{e f}^{(c i)}}{\varepsilon_{f p}}\right)
$$


Therefore, $T L_{(I T M)}$ can be expressed by:

$$
T L_{(I T M)}=\frac{2\left(1-e^{-B L_{b} / 2}\right)}{B}
$$

Using practical values for $B$ and $L_{b}, e^{-B L_{b} / 2}$ is always a very small number when compared to the other terms, and can be ignored. Hence, by rewriting Eq. (20), $T L_{(I T M)}$ can be obtained, as follows:

$$
T L_{(I T M)}=\frac{2}{B} \rightarrow B=\left(\frac{2 k_{e}}{a_{f} \cdot E_{f}}\right)^{0.5}
$$

This equation evidences that the prestress transfer length is directly related to the stiffness parameter $(B)$. In fact, the $B$ parameter represents physically the relative stiffness of the materials surrounding the CFRP reinforcement and the stiffness of this last one.

\section{Assessment of Predictive Performance of Analytical Approach}

The performance of the described analytical approach is assessed by predicting the distribution of the normalized tensile strain in the CFRP reinforcement and the bond shear stress for all the prestressed strengthened beams immediately after the release of the prestress force. The relationship between the aforementioned terms obtained analytically and experimentally versus distance from the end of CFRP bonded length is depicted in Figures $8 \mathrm{~b}$ and 9. These figures indicate a good predictive performance of the analytical approach in terms of distribution of the CFRP tensile strain and bond shear stress along the CFRP bonded length when the prestress force is released. Besides, Figure $8 \mathrm{~b}$ evidences that the analytical model predicts with good accuracy the normalized effective tensile strain in the CFRP laminate $\left(\varepsilon_{e f}^{(c i)} / \varepsilon_{f p}\right)$ registered experimentally, beyond the transmission zone.

The proposed analytical model is, moreover, applied on the prediction of the distribution of the CFRP tensile strain and bond shear stress of the RC beams strengthened with either prestressed spirally wound rod or sand blasted CFRP rod, whose tests were conducted by Badawi et al. (2010) [31]. The data defining the geometry and reinforcement details, as well as the main material properties of this experimental program is included in Table 2. The distribution of normalized tensile strain in the spirally CFRP rods and in the sand blasted CFRP rods obtained analytically and 
registered experimentally for these beams is compared in Figures 10a and 10b, respectively. Furthermore, Figures 10c and 10d compare the bond shear stress distribution predicted analytically and recorded experimentally in the cases of 45\% prestressed spirally CFRP rod and 40\% prestressed sand blasted CFRP rod, respectively.

By considering the relationship between $\varepsilon_{f} / \varepsilon_{f p}$ and the distance from the end of the CFRP bonded length registered experimentally in the program carried out in the present work (Figure 8b) and in the program executed by Badawi et al. (2010) (Figures 10a and 10b), the two analytical approaches (95\%ASM and ITM) are applied in order to determine the prestress transfer length $(T L)$, whose results are presented in Table 3.

In fact, in the cases of beams reported by [31], experimental distribution of the CFRP tensile strain along the bonded length represented in Figures 10a and 10b showed more gradually increasing than the corresponding analytical ones during the transfer length, resulting in a lower bond shear stress and higher transfer length for the experimental results. The higher increase rate of the $\varepsilon_{f} / \varepsilon_{f p}$ predicted analytically than the one registered experimentally may be attributed to the following reasons: 1) better bond behavior of the equivalent square cross section for the CFRP (used in the analytical model) compared to its round cross section (used in experimental program) due to a higher contact perimeter, 2) damages in the CFRP-adhesive-concrete bonds within the transmission zone due to a high possible rate of the prestress releasing in the laboratory and/or due to a deficient filling of the groove with the epoxy because of the relatively small thickness of the groove.

It should be noted that Poisson's ratio of the epoxy adhesive $\left(v_{a}\right)$ used in the analytical approach for the simulation of the experimental tests and the beams tested by [31] was assumed 0.33 and 0.49 , respectively, according to the recommendation of [32] considering the corresponding elasticity modulus of adhesive ( $\left.E_{a}\right)$. Moreover, the effects of preloading on the existing structures were neglected to simulate the aforementioned experimental programs.

\section{Parametric Study}

By using the developed analytical model, parametric studies were carried out to evaluate the influence of the relevant parameters of this model on the distribution of CFRP tensile strain $\left(\varepsilon_{f}\right)$ and bond shear stress $(\tau)$, as well as on the prestress transfer length $(T L)$. The parameters considered in this parametric study were: the elasticity modulus of 
concrete, CFRP, and adhesive; the shape of CFRP cross section; the thickness of adhesive layer; and the curing time of the epoxy adhesive. For an easier interpretation of the influence of these parameters on the distribution of $\varepsilon_{f}, \tau$ and on the $T L$ values, these results were normalized (divided by) to, respectively, the initial prestrain applied to the laminate $\left(\varepsilon_{f p i}\right)$, maximum bond shear stress obtained analytically at the end section of CFRP bonded length $\left(\tau_{i}\right)$, and prestress transfer length obtained analytically by using the ITM method $\left(T L_{i}\right)$ applied to the experimental beams (Table 3).

\subsection{Material properties}

Figure 11 shows the influence of the normalized elasticity modulus of concrete $\left(E_{c} / E_{c i}\right)$, CFRP $\left(E_{f} / E_{f i}\right)$, and adhesive $\left(E_{a} / E_{a i}\right)$, on the normalized CFRP tensile strain $\left(\varepsilon_{f} / \varepsilon_{f p i}\right)$, normalized bond shear stress $\left(\tau / \tau_{i}\right)$, and normalized prestress transfer length $\left(T L / T L_{i}\right)$ obtained according to the ITM method, where $E_{c i}, E_{f i}$, and $E_{a i}$ are the elasticity modulus of concrete, CFRP, and adhesive as reported in Table 1. It should be noted that an equal variation ratio $(0.5,1$, and 2$)$ was adopted for the aforementioned properties in order to facilitate the comparison of the influence of the variation of different material properties on the investigated terms.

The results show that the increase of the elasticity modulus of concrete and adhesive reduces the prestress transfer length (Figures $11 \mathrm{~b}$ and 11d), but increases the maximum bond shear stress causing a higher possibility of damage in the concrete substrate (Figures 11a and 11c). In fact, the effective bond stiffness $\left(k_{e}\right)$ increases with the shear stiffness of adhesive layer $\left(k_{a}\right)$ and concrete layer $\left(k_{c}\right)$, causing a higher stiffness parameter $(B)$, resulting a decrease of the prestress transfer length (see Eq. (21)) and an increase of the bond shear stress (see Eq. (17)).

On the other hand, a higher elasticity modulus of CFRP reinforcement resulted in a longer transfer length and a smaller maximum bond shear stress (Figures 11e and 11f). In fact, a higher elasticity modulus of CFRP reinforcement decreases the stiffness parameter, $B$, resulting in a longer prestress transfer length according to the Eq. (21).

\subsection{CFRP and groove cross section}


The most common CFRP bar types for the flexural strengthening of RC beams according to NSM technique have cross section of rectangular, square or circular shape. The experimental research has evidenced a better bond behavior of the CFRP bar of rectangular cross section when compared to the other types of bars due to the higher ratio of the bond contact area to the cross sectional area [33].

Figure 12a shows a comparison between the use of rectangular and square CFRP bars with equal cross sectional area and thickness of the adhesive layer (designated by $C 1$ and $C 2$, respectively) in terms of the normalized CFRP tensile strain $\left(\varepsilon_{f} / \varepsilon_{f p i}\right)$ and bond shear stress $\left(\tau / \tau_{i}\right)$. According to this figure, the CFRP bar with square shape increased significantly the maximum bond shear stress when compared to the use of rectangular CFRP bar due to the direct influence of $a_{f}$ on the $\tau$, according to Eq. (1).

The higher bond contact area of the rectangular CFRP bar, moreover, caused analytically a decrease in terms of prestress transfer length when compared to the use of square CFRP bar, as represented in Figure 12b. This figure evidences that the use of square CFRP bar $\left(a_{f} / b_{f}=1\right.$, where $a_{f}$ and $b_{f}$ are width and height of the CFRP cross section) provides an increase of $51 \%$ in terms of prestress transfer length according to the ITM method compared to the use of rectangular CFRP bar with $a_{f} / b_{f}=0.07$. In other words, a higher width/height ratio $\left(a_{f} / b_{f}\right)$ of the CFRP cross section increases the prestress transfer length.

On the other side, Figures $12 \mathrm{c}$ and $12 \mathrm{~d}$ show the influence of the normalized adhesive layer thickness $\left(t_{a} / t_{a i}\right)$ on the normalized terms of CFRP tensile strain $\left(\varepsilon_{f} / \varepsilon_{f p i}\right)$, bond shear stress $\left(\tau / \tau_{i}\right)$, and prestress transfer length $\left(T L / T L_{i}\right)$, where $t_{a i}$ is the thickness of adhesive layer adopted for the experimental program (as represented in Figure 1). These figures evidence that the prestress transfer length increases with the adhesive layer thickness due to the decrease of the adhesive shear stiffness $\left(k_{a}\right)$, resulting a lower effective bond stiffness $\left(k_{e}\right)$.

\subsection{Transfer length during the epoxy curing time}

This section aims to identify a time at which the epoxy adhesive provides the minimum structural requirements in terms of prestress transfer length to release the prestress force applied to the NSM CFRP reinforcement. For this period 
of time, the evolution of the elasticity modulus of the type of epoxy adhesive $\left(E_{a}\right)$ adopted in the present experimental program can be obtained using Eq. (22) [34]. Accordingly, the evolution of the shear modulus of the epoxy adhesive during this period can be obtained using Eq. (3) neglecting the influence of the evolution of the Poisson's ratio of the epoxy adhesive, as follows:

$$
E_{a}(t)=E_{a} \cdot e^{\left(-\frac{1}{2}\left(\frac{\omega}{t}\right)^{\alpha}\right)} \rightarrow G_{a}(t)=G_{a} \cdot e^{\left(-\frac{1}{2}\left(\frac{\omega}{t}\right)^{\alpha}\right)}
$$

where $\omega$ and $\alpha$ are shape parameter $(\omega=12.926)$ and time parameter $(\alpha=2.779)$, respectively. $E_{a}(t)$ and $G_{a}(t)$ are elasticity and shear modulus of the epoxy adhesive at a given time, $t$, from the onset of groove injection with $\operatorname{epoxy}(t=0)$.

Hence, the effective bond stiffness $\left(k_{e}(t)\right)$ can be derived using shear stiffness of the adhesive layer $\left(k_{a}(t)\right)($ with Eq. (2)) during the epoxy curing time, as follows:

$$
k_{a}(t)=\frac{G_{a} \cdot e^{\left(-\frac{1}{2}\left(\frac{\omega}{t}\right)^{\alpha}\right)}}{t_{a}} \rightarrow k_{e}(t)=\left(\frac{k_{c}}{1+\frac{k_{c}}{k_{a}(t)}}\right)
$$

Therefore, during the curing time of epoxy adhesive, the evolution of the prestress transfer length can be obtained by:

$$
T L_{(I T M)}(t)=\frac{2}{B} \rightarrow B(t)=\left(\frac{2 k_{e}(t)}{a_{f} \cdot E_{f}}\right)^{0.5}
$$

Figure 13a represents the evolution of the shear modulus during the hardening process of the epoxy adhesive in its curing time, resulting an increase of the effective bond stiffness during this period. The hardening of the epoxy adhesive during its curing time leads to a decrease of the prestress transfer length, as shown in Figure $13 \mathrm{~b}$.

\section{Conclusion}

The current study aimed to experimentally and analytically investigate the prestress transfer length and distribution of CFRP tensile strain and bond shear stress, immediately after the release of the prestress force, in the context of using 
NSM CFRP reinforcement for the flexural strengthening of RC beams. According to the observed results, the following conclusions can be drawn:

- The experimental results showed that the distribution of tensile strain in the extremity regions of the CFRP bonded length varies from zero (at its end section) to its effective tensile strain during the prestress transfer length, and reaches a plateau beyond this length. Moreover, the results evidenced that the prestress level applied to the CFRP reinforcement has a negligible influence on the prestress transfer length.

- The experimental investigation demonstrated that the bond shear stress starts from high value at the end of the CFRP bonded length and continues decreasing along the prestress transfer length, and becomes approximately null after that. This bond shear stress increases with the prestress force applied to the NSM CFRP reinforcement.

- Simple analytical equations are proposed to predict the distribution of CFRP tensile stress and bond shear stress along the NSM CFRP bonded length when the prestress force is released.

- An analytical formulation, with a design framework, is developed based on the closed form solution for the prediction of prestress transfer length by considering the influence of the effective parameters on this length.

- The results of two experimental programs composed of RC beams strengthened with prestressed NSM CFRP reinforcement, in terms of distribution of CFRP tensile strain and bond shear stress, and prestress transfer length, were compared with the ones obtained by the proposed analytical approach, and a good predictive performance was determined.

- From the analytical parametric studies it was verified that by increasing the elasticity modulus of the concrete and epoxy adhesive the prestress transfer length decreases and the bond shear stress increases, while the opposite occurs with the increase of the CFRP elasticity modulus. Moreover, by increasing the thickness of epoxy adhesive layer, the prestress transfer length increases. On the other side, the CFRP reinforcement with rectangular cross section requires a lower transfer length compared to the use of square cross section with equal cross sectional area. In other words, a higher width/height ratio $\left(a_{f} / b_{f}\right)$ of the CFRP cross section increases the prestress transfer length. 
- A formula is analytically proposed to predict the evolution of the prestress transfer length during the curing time of epoxy adhesive by inspired on the evolution of the elasticity modulus of epoxy adhesive during this period.

\section{Acknowledgement}

The study reported in this paper is part of the project "PreLami - Performance of reinforced concrete structures strengthened in flexural with an innovative system using prestressed NSM CFRP laminates", with the reference PTDC/ECM/114945/2009. The authors would also like to acknowledge the support provided by CLEVER Reinforcement Iberica Company, for supplying the adhesives and the laminates, and Casais and CiviTest for the preparation of the beams.

\section{Notations}

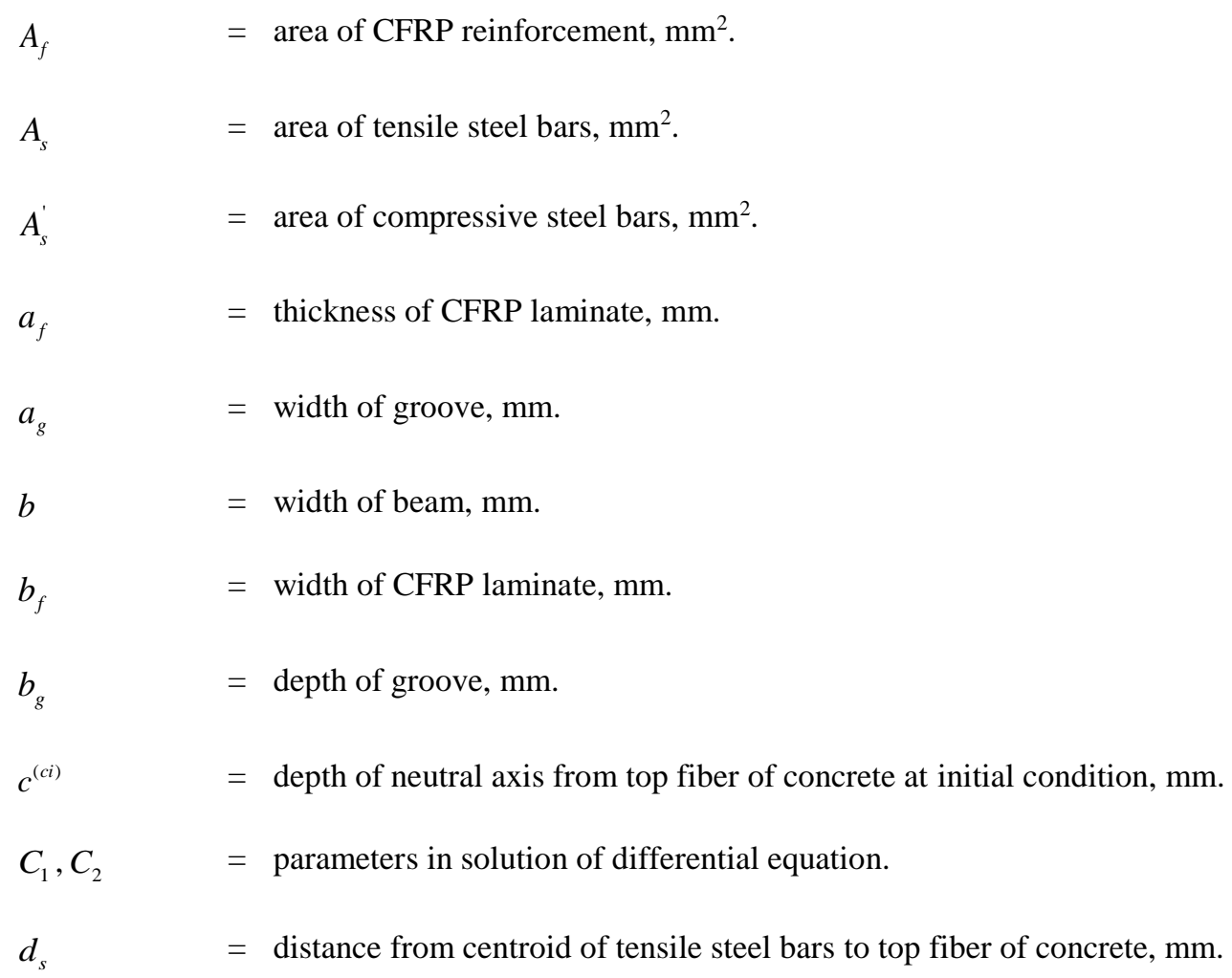




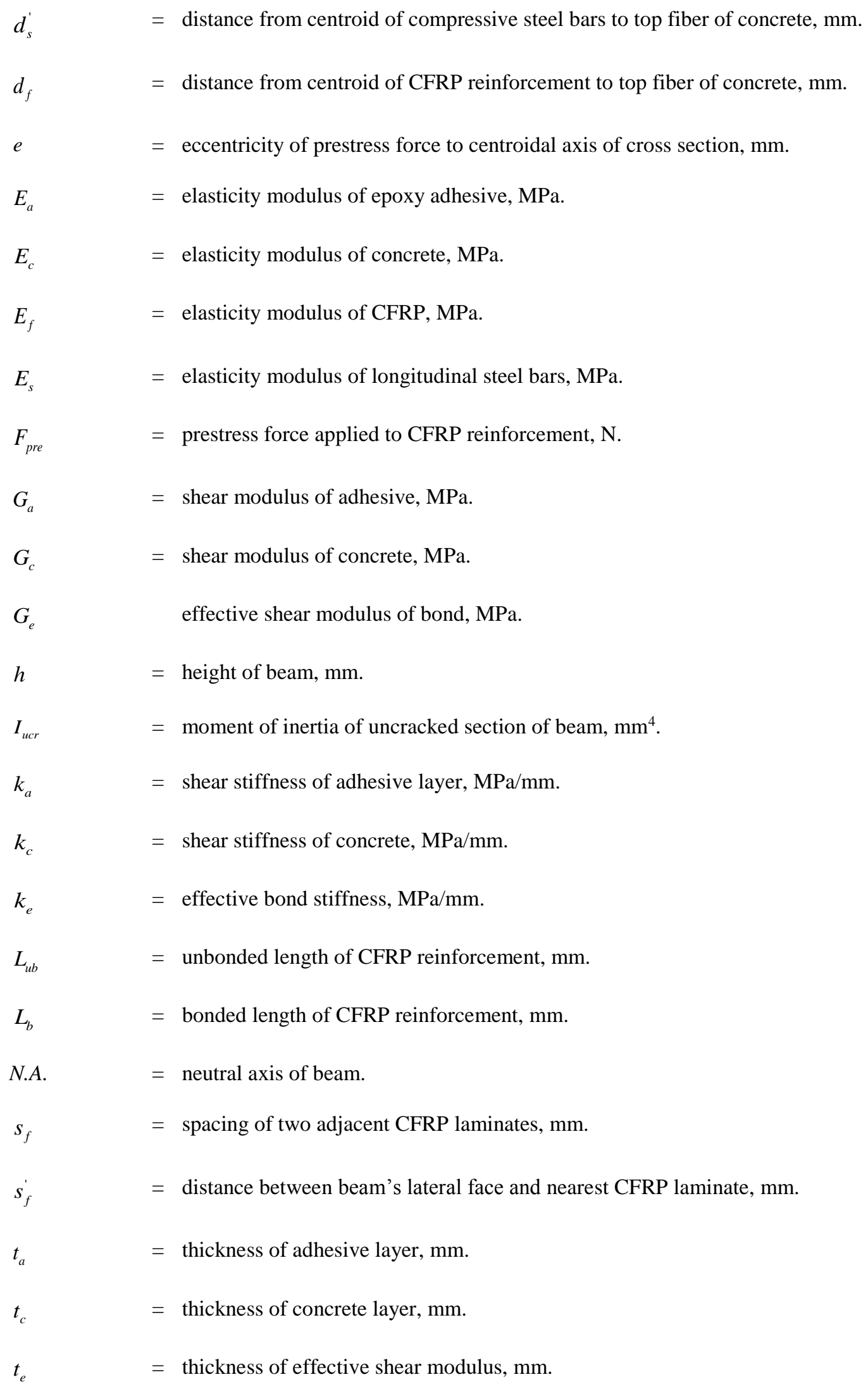




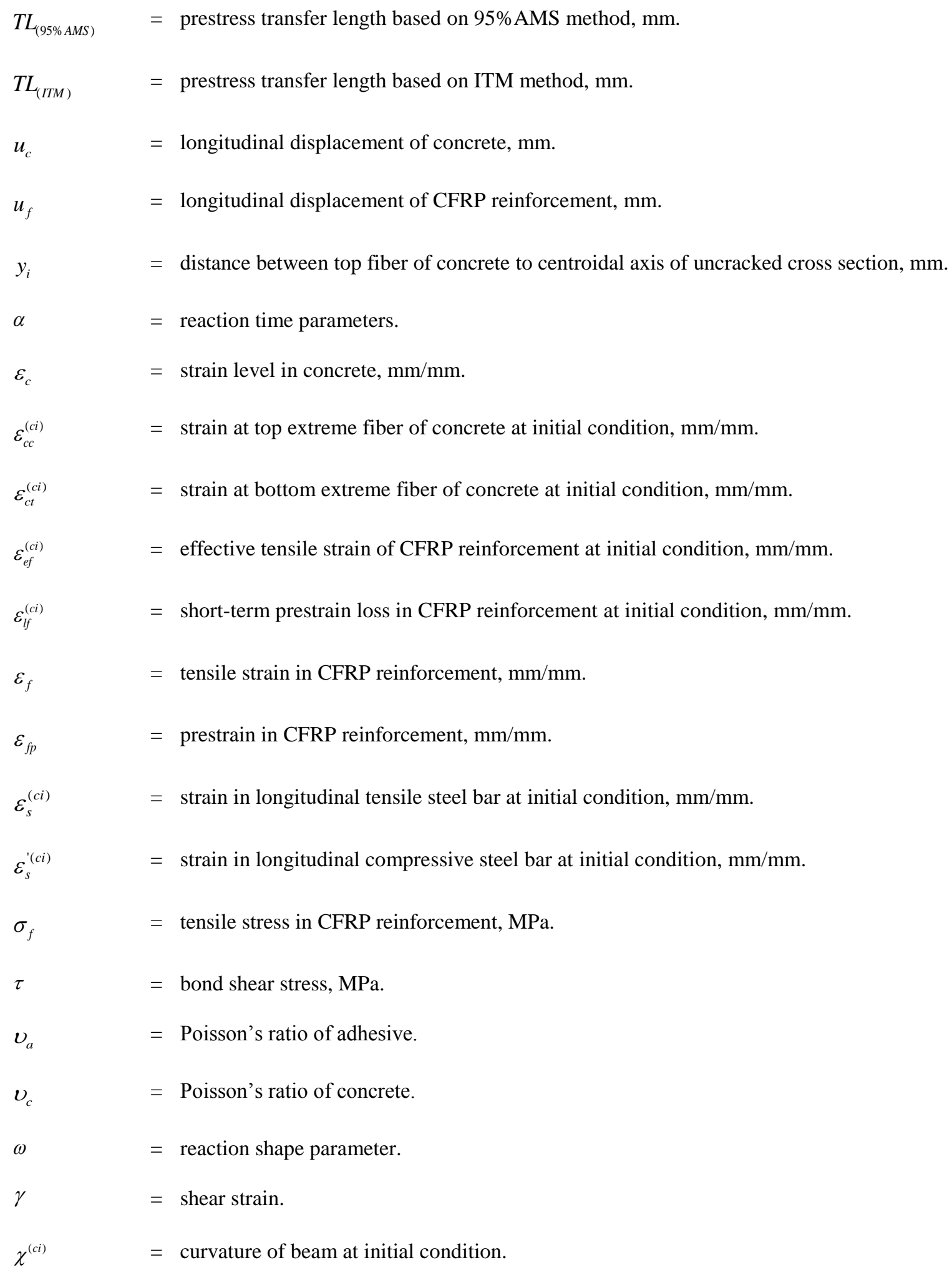

\section{Appendix A}


After the release of the prestress force, a tensile strain at the top fiber $\left(\varepsilon_{c c}^{(c i)}\right)$ and a compressive strain at the bottom fiber $\left(\varepsilon_{c t}^{(c i)}\right)$ of concrete occurs due to the initial negative camber, whose equations are provided in the following:

$$
\begin{gathered}
\varepsilon_{c c}^{(c i)}=\frac{\left(\left(\frac{F_{p r e} \cdot e \cdot y_{i}}{I_{u c r}}\right)-\left(\frac{F_{p r e}}{b \cdot h}\right)\right)}{E_{c}}-\frac{y_{i} \cdot \varepsilon_{c t i}}{\left(h-y_{i}\right)} \\
\varepsilon_{c t}^{(c i)}=\frac{\left(\left(\frac{F_{p r e} \cdot e \cdot\left(h-y_{i}\right)}{I_{u c r}}\right)+\left(\frac{F_{p r e}}{b . h}\right)\right)}{E_{c}}-\varepsilon_{c t i}
\end{gathered}
$$

where $I_{u c r}$ is moment of inertia of uncracked section. $b$ and $h$ are width and height of beam cross section, respectively. Moreover, $\varepsilon_{c t i}$ is the initial tensile strain level on the concrete tensile surface due to the load conditions existing in the structure to be strengthened before application of FRP reinforcement (preloading). This strain level can be estimated according to the recommendation of ACI 440.2R (Figures 5, 6, and 7) [1].

The curvature corresponding to the initial negative camber of the prestressed strengthened beams $\left(\chi^{(c i)}\right)$ can be determined by considering the neutral axis depth from the extreme top fiber of concrete $\left(c^{(c i)}\right)$ :

$$
c^{(c i)}=\frac{\varepsilon_{c c}^{(c i)} \cdot h}{\left(\varepsilon_{c c}^{(c i)}+\varepsilon_{c t}^{(c i)}\right)} \rightarrow \chi^{(c i)}=\frac{\varepsilon_{c c}^{(c i)}}{c^{(c i)}}
$$

Moreover, strains in the compressive and tensile steel bars can be obtained by:

$$
\begin{aligned}
& \varepsilon_{s}^{\prime(c i)}=\frac{\varepsilon_{c c}^{(c i)} \cdot\left(c^{(c i)}-d_{s}^{\prime}\right)}{c^{(c i)}} \\
& \varepsilon_{s}^{(i)}=\frac{\varepsilon_{c c}^{(c i)} \cdot\left(d_{s}-c^{(c i)}\right)}{c^{(c i)}}
\end{aligned}
$$

It should also be noted that Eqs. (A1) - (A5) are derived by assuming no cracking occurs after the release of the prestress force (Figures 5 and 7). A more detailed description of the analytical model reported in Appendix A can be found elsewhere $[24,35]$. 


\section{References}

1. ACI-440.2R. Guide for the Design and Construction of Externally Bonded FRP Systems for Strengthening Concrete Structures. American Concrete Institute, 2008.

2. Barros J, Dias S and Lima J. Efficacy of CFRP-based Techniques for the Flexural and Shear Strengthening of Concrete Beams. Cement and Concrete Composites, 2007;29(3).

3. Bilotta A, Ceroni F, Nigro E and Pecce M. Bond Behavior of FRP NSM Systems in Concrete Elements. Composite Part B: Engineering, 2012;43(2):99-109.

4. Ascione L, Berardi V, Feo L and Mancusi G. A numerical evaluation of the interlaminar stress state in externally FRP plated RC beams. Composite Part B: Engineering, 2005; 36.

5. Yuan H, Lu X, Hui D and Feo L. Studies on FRP-concrete interface with hardening and softening bond-slip law. Composite Structures, 2012; 94.

6. Mazaheripour H, Barros J, Sena-Cruz J and Soltanzadeh F. Analytical bond model for GFRP bars to steel fiber reinforced self-compacting concrete. Journal of Composites for Construction, 2013;17(6).

7. Ascione L and Berardi V. Anchorage device for FRP laminates in the strengthening of concrete structures close to beam-column joints. Composite Part B: Engineering, 2011; 42.

8. Xiong G, Jiang X, Liu J and Chen L. A way for preventing tension delamination of concrete cover in midspan of FRP strengthened beams. Construction and Building Materials, 2007; 21.

9. Nordin H and Taljsten B. Concrete Beams Strengthened with Prestressed Near Surface Mounted CFRP. Journal of Composites for Construction, 2006;10(1):60-8.

10. Badawi M and Soudki K. Flexural Strengthening of RC Beams with Prestressed NSM CFRP RodsExperimental and Analytical Investigation. Construction and Building Materials. 2009:3292-300.

11. Hajihashemi A, Mostofinejad D and Azhari M. Investigation of RC Beams Strengthened with Prestressed NSM CFRP Laminates. Journal of Composites for Construction (ASCE). 2011;15(6.).

12. Kotynia R, Walendziak R, Stoecklin I and Meier U. RC Slabs Strengthened with Prestressed and Gradually Anchored CFRP Strips Under Monotonic and Cyclic Loading. Journal of Composites for Construction, $2011 ; 15(2)$.

13. Rezazadeh M, Costa I and Barros J. Influence of Prestress Level on NSM CFRP Laminates for the Flexural Strengthening of RC Beams. Composite Structures. 2014;116:489-500. 
14. Choi H, West J and Soudki K. Effect of Partial Unbonding on Prestressed Near-Surface-Mounted CFRPStrengthened Concrete T-Beams. Journal of Composites for construction (ASCE). 2011;15(1.).

15. Rezazadeh M and Barros J. A New Hybrid Methodology According to Near Surface Mounted Carbon Fiber Reinforced Polymer Technique for the Flexural Strengthening of Reinforced Concrete Beams. Reinforced Plastics and Composites. 2014;33(21):1993-2009.

16. Huang J, Huang P and Zheng X. Experimental study of prestress losses of RC beams strengthened with prestress FRP. Journal of Building Structures. 2015; 36(1): 85-91.

17. Abdelatif A, Owen J and Hussein M. Modelling the Prestress Transfer in Pre-tensioned Concrete Elements. Finite Elements in Analysis and Design. 2014;94:47-63.

18. E365. Hardened Concrete - Determination of the modulus of elasticity of concrete in compression. 1993: National Laboratory for Civil Engineering Specification.

19. EN 10002-1. Metallic materials-Tensile testing. Part 1: Method of test. 1990: European standard.

20. ISO 527-5. Plastics-determination of tensile properties-Part 5: Test conditions for unidirectional fibrereinforced plastic composites. 1997: International Organization for Standardization (ISO).

21. ISO 527-2. Plastics-determination of tensile properties-Part 2: test conditions for moulding and extrusion plastics. 1993: International Organization for Standardization (ISO).

22. Malek A, Saadatmanesh H and Ehsani M. Prediction of Failure Load of RC beams Strengthened with FRP Plate Due to Stress Concentration at the Plate End. ACI Structural Journal. 1998;95.

23. Hassan T and Rizkalla S. Investigation of Bond in Concrete Structures Strengthened with Near Surface Mounted Carbon Fiber Reinforced Polymer Strips. Journal of Composites for Construction. 2003;7(3).

24. Rezazadeh M, Barros J and Costa I. Analytical Approach for the Flexural Analysis of RC Beams Strengthened with Prestressed CFRP. Composite Part B: Engineering. 2015, 73, 16-34.

25. Dai J, Ueda T and Sato Y. Development of the Nonlinear Bond Stress-Slip Model of Fiber Reinforced Plastics Sheet-Concrete Interfaces with a Simple Method. Journal of Composites for Construction. 2005;9(1).

26. Faella C, Martinelli E and Nigro E. Interface Behaviour in FRP Plates Bonded to Concrete: Experimental Tests and Theoretical Analyses. In: Proceedings of Advanced Materials for Construction of Bridges, Buildings, and Other Structures III Conference, 2003. 
27. Toutanji H, Han M and Ghorbel E. Interfacial Bond Strength Characteristics of FRP and RC Substrate. Journal of Composites for Construction. 2012;16(1).

28. De Lorenzis L and Teng J. Near-Surface Mounted FRP Reinforcement: an Emerging Technique for Structural Strengthening. Composite Part B: Engineering. 2007;39(2):119-49.

29. Wu Z, Yang S and Zheng J. An Analytical Model For Rectangular RC Beams Reinforced with Prestressed CFRP Plates. In: Proceedings of Our World in Concrete \& Structures. 30th Conference, 2005.

30. Russell B and Burns N. Design Guidlines for Transfer, Development and Bebonding of Large Diameter Seven Wire Strands in Pretensioned Concrete Girders. 1993: University of Texas.

31. Badawi M, Wahab N, and Soudki K. Evaluation of the Transfer Length of Prestressed Near Surface Mounted CFRP Rods in Concrete. Construction and Building Materials. 2010. p. 1474-1479.

32. He X. Effect of Mechanical Properties of Adhesive on Stress Distributions in Structural Bonded Joints. In: Proceedings of the World Congress on Engineering Vol II. Conference, 2010.

33. El-Hacha R and Rizkalla S. Near-Surface-Mounted Fiber-Reinforced Polymer Reinforcements for Flexural Strengthening of Concrete Structures. ACI Structural Journal. 2004;101(5):717-26.

34. Fernandes P, Granja J, Benedetti A, Sena-Cruz J and Azenha M. Quality Control and Monitoring of NSM CFRP System: E-modulus Evolution of Epoxy Adhesive and its Relation to the Pull-out Force. Composite Part B: Engineering, 2015, 75, pp:95-103.

35. Rezazadeh M, Barros J and Costa I. Analytical Model for the Prediction of the Behavior of RC Beams Flexurally Strengthened with Prestressed NSM CFRP Laminates. Report $n^{\circ}$ 2014-DEC/E-04, University of Minho, 2014. 
Table 1: Average values of the main properties of the constituent materials

\begin{tabular}{|c|c|c|c|c|c|c|c|}
\hline \multirow{2}{*}{ Concrete } & Number & \multicolumn{3}{|c|}{ Compressive strength } & \multicolumn{3}{|c|}{ Young's modulus } \\
\hline & 3 & \multicolumn{3}{|c|}{$f_{c m}=32.2 \mathrm{MPa}$} & \multicolumn{3}{|c|}{$E_{c}=27 \mathrm{GPa}$} \\
\hline \multirow{3}{*}{ Steel bars } & $\begin{array}{c}\text { Number } \\
\text { of samples }\end{array}$ & Diameter & \multicolumn{2}{|c|}{$\begin{array}{l}\text { Yield initiation } \\
\text { strength }\end{array}$} & \multicolumn{2}{|c|}{$\begin{array}{c}\text { Tensile } \\
\text { strength }\end{array}$} & $\begin{array}{l}\text { Elasticity } \\
\text { modulus }\end{array}$ \\
\hline & 4 & $6 \mathrm{~mm}$ & \multicolumn{2}{|c|}{$f_{\text {sym }}=613 \mathrm{MPa}$} & \multicolumn{2}{|c|}{$f_{\text {sum }}=696 \mathrm{MPa}$} & $E_{s}=218 \mathrm{GPa}$ \\
\hline & 5 & $10 \mathrm{~mm}$ & \multicolumn{2}{|c|}{$f_{\text {sym }}=585 \mathrm{MPa}$} & \multicolumn{2}{|c|}{$f_{\text {sum }}=656 \mathrm{MPa}$} & $E_{s}=208 \mathrm{GPa}$ \\
\hline \multirow{2}{*}{$\begin{array}{c}\text { CFRP } \\
\text { laminate }\end{array}$} & $\begin{array}{c}\text { Number } \\
\text { of samples }\end{array}$ & \multicolumn{2}{|c|}{ Tensile strength } & \multicolumn{2}{|c|}{$\begin{array}{c}\text { Ultimate tensile } \\
\text { strain }\end{array}$} & & $\begin{array}{l}\text { Elasticity } \\
\text { modulus }\end{array}$ \\
\hline & 4 & \multicolumn{2}{|c|}{$f_{\text {fum }}=1922 \mathrm{MPa}$} & \multicolumn{2}{|c|}{$\varepsilon_{\text {fum }}=11.7(\%)$} & & $=164 \mathrm{GPa}$ \\
\hline \multirow{2}{*}{$\begin{array}{c}\text { Epoxy } \\
\text { adhesive }\end{array}$} & $\begin{array}{c}\text { Number } \\
\text { of samples }\end{array}$ & \multicolumn{3}{|c|}{ Tensile strength } & \multicolumn{3}{|c|}{ Elasticity modulus } \\
\hline & 5 & \multicolumn{3}{|c|}{$f_{a m}=20 \mathrm{MPa}$} & \multicolumn{3}{|c|}{$E_{a}=7 \mathrm{GPa}$} \\
\hline
\end{tabular}


Table 2: Geometries and main material properties of the tested beams by Badawi et al. (2010)

\begin{tabular}{c|cccccccccc}
\hline & $\begin{array}{c}L_{b} \\
\text { Geometries }\end{array}$ & $\begin{array}{c}b \\
(\mathrm{~mm})\end{array}$ & $\begin{array}{c}h \\
(\mathrm{~mm})\end{array}$ & $\begin{array}{c}d_{s} \\
(\mathrm{~mm})\end{array}$ & $\begin{array}{c}d_{f} \\
(\mathrm{~mm})\end{array}$ & $\begin{array}{c}A_{s}^{\prime} \\
\left(\mathrm{mm}^{2}\right)\end{array}$ & $\begin{array}{c}A_{s} \\
\left(\mathrm{~mm}^{2}\right)\end{array}$ & $\begin{array}{c}A_{f} \text { spirally } \\
\text { wound } \\
\left(\mathrm{mm}^{2}\right)\end{array}$ & $\begin{array}{c}A_{f} \text { sand } \\
\text { blasted } \\
\left(\mathrm{mm}^{2}\right)\end{array}$ & $\begin{array}{c}\text { groove } \\
\text { size } \\
\left(\mathrm{mm}^{2}\right)\end{array}$ \\
\cline { 2 - 9 } & 3300 & 152 & 254 & 209 & 241.5 & 200 & 400 & $1 \varphi 9$ & $1 \varphi 9.5$ & $15 \times 25$ \\
\hline
\end{tabular}

$L_{b}$ : CFRP bonded length, $b$ and $h$ : width and height of beam cross section, $A_{s}^{\prime}$ : area of compressive steel bar, $A_{s}$ and $d_{s}$ : area of tensile steel bar and its depth from top fiber of section, $A_{f}$ and $d_{f}$ : area of CFRP reinforcement and its depth from top fiber of section.

\begin{tabular}{c|c|cc|cc|cc|cc}
\hline \multirow{4}{*}{$\begin{array}{c}\text { Material } \\
\text { properties }\end{array}$} & Concrete & \multicolumn{2}{|c|}{ Steel bars } & \multicolumn{2}{c|}{ CFRP spirally wound } & \multicolumn{2}{c|}{ CFRP sand blasted } & \multicolumn{2}{c}{ Epoxy adhesive } \\
\cline { 2 - 10 } & $(\mathrm{MPa})$ & $\begin{array}{c}f_{\text {sym }}^{\prime} \\
(\mathrm{MPa})\end{array}$ & $\begin{array}{c}f_{\text {sum }} \\
(\mathrm{MPa})\end{array}$ & $\begin{array}{c}E_{f} \\
(\mathrm{GPa})\end{array}$ & $\begin{array}{c}f_{\text {fum }} \\
(\mathrm{MPa})\end{array}$ & $\begin{array}{c}E_{f} \\
(\mathrm{GPa})\end{array}$ & $\begin{array}{c}f_{\text {fum }} \\
(\mathrm{MPa})\end{array}$ & $\begin{array}{c}E_{a} \\
(\mathrm{GPa})\end{array}$ & $\begin{array}{c}f_{\text {am }} \\
(\mathrm{MPa})\end{array}$ \\
\cline { 2 - 11 } & 45 & 440 & 560 & 136 & 1970 & 130 & 2166 & 4.48 & 24.8 \\
\hline
\end{tabular}

$f_{c m}^{\prime}$ : concrete compressive strength, $f_{\text {sym }}$ and $f_{\text {sum }}$ : yield and ultimate tensile strength of steel bars, $E_{f}$ and $f_{\text {fum }}$ : elasticity modulus and tensile strength of CFRP, $E_{a}$ and $f_{a m}$ : elasticity modulus and tensile strength of adhesive. 
Table 3: Comparison of prestress transfer length $(T L)$ for the tested beams

\begin{tabular}{c|cccccc}
\hline Beams & $T L_{(95 A M S)}^{\exp }$ & $T L_{(I T M)}^{\exp }$ & $T L_{(95 A M S)}^{\text {analy }}$ & $T L_{(I T M)}^{\text {analy }}$ & $\frac{T L_{(95 A M S)}^{\text {exp }}}{T L_{(95 A M S)}^{\text {analy }}}$ & $\frac{T L_{(I T M)}^{\exp }}{T L_{(I T M)}^{\text {analy }}}$ \\
\hline $\begin{array}{c}\text { Experimental beams } \\
\begin{array}{c}\text { Tested by Badawi et al. } \\
\text { (spirally wound) }\end{array}\end{array}$ & 281 & 200 & 145 & 94 & 1.93 & 2.13 \\
\hline $\begin{array}{c}\text { Tested by Badawi et al. } \\
\text { (sand blasted) }\end{array}$ & 208 & 148 & 140 & 92 & 1.48 & 1.60 \\
\hline
\end{tabular}



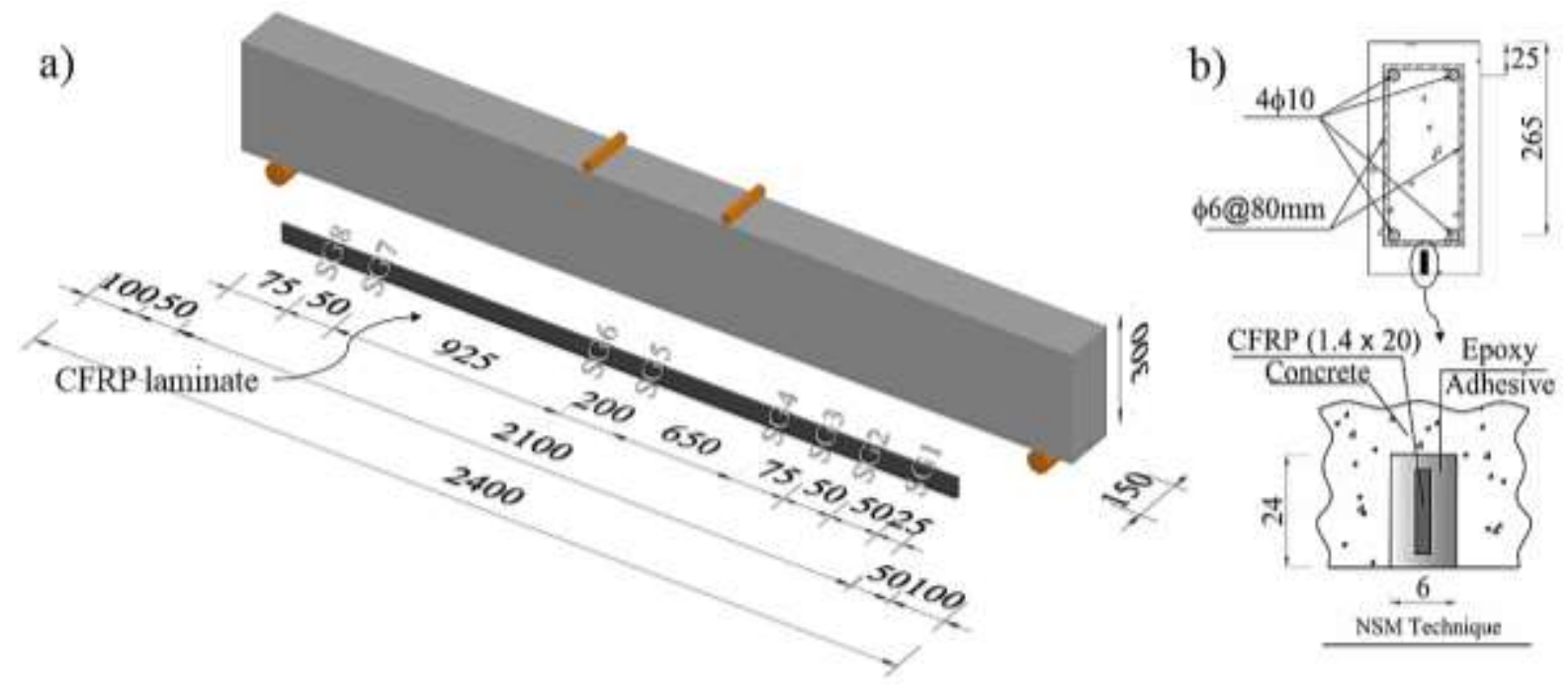

Figure 1: The beams of the experimental program: a) geometry and position of strain gauges (SG) installed on the CFRP laminate; b) steel and CFRP reinforcements (dimensions in $\mathrm{mm}$ ) 


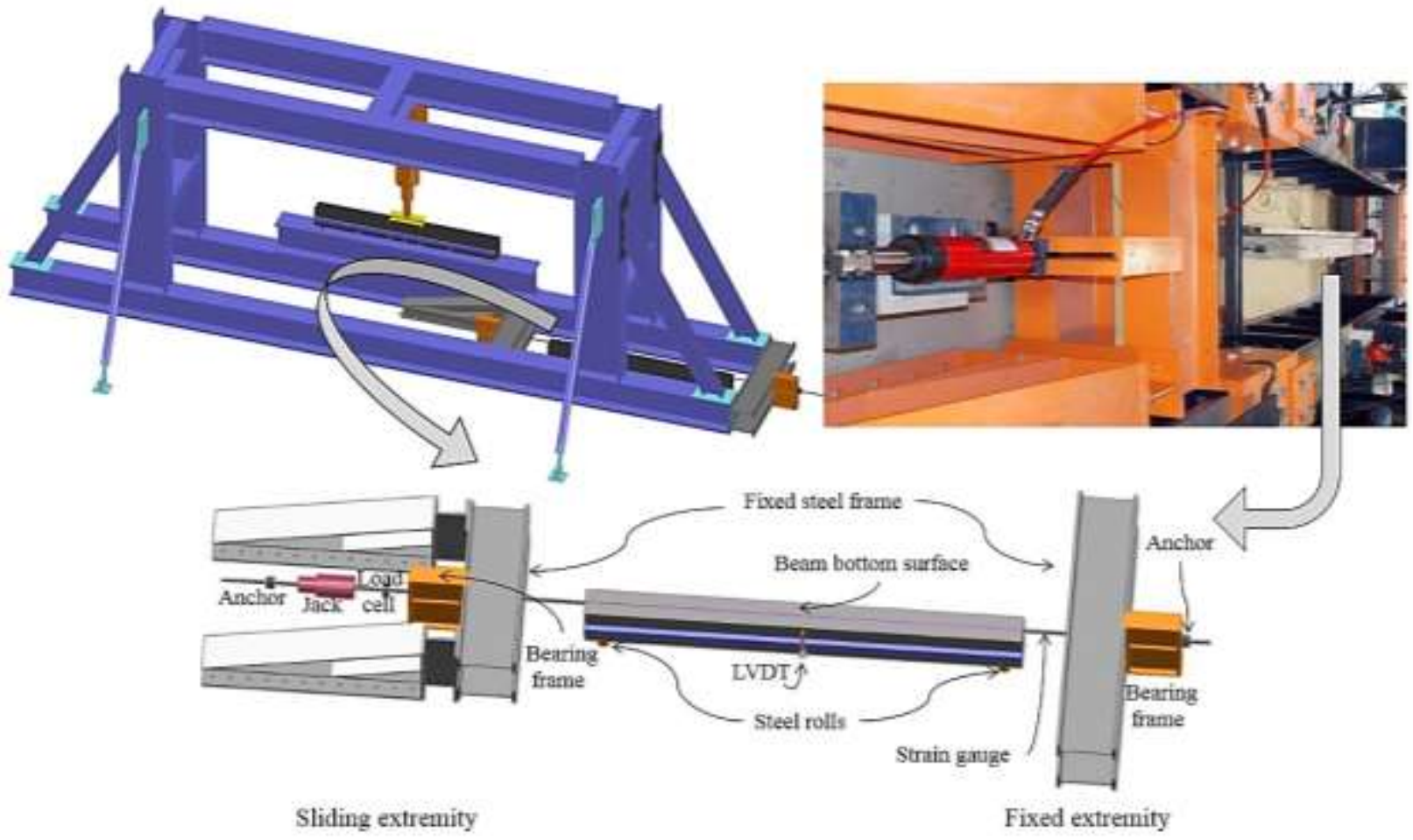

Figure 2: Prestressing setup 

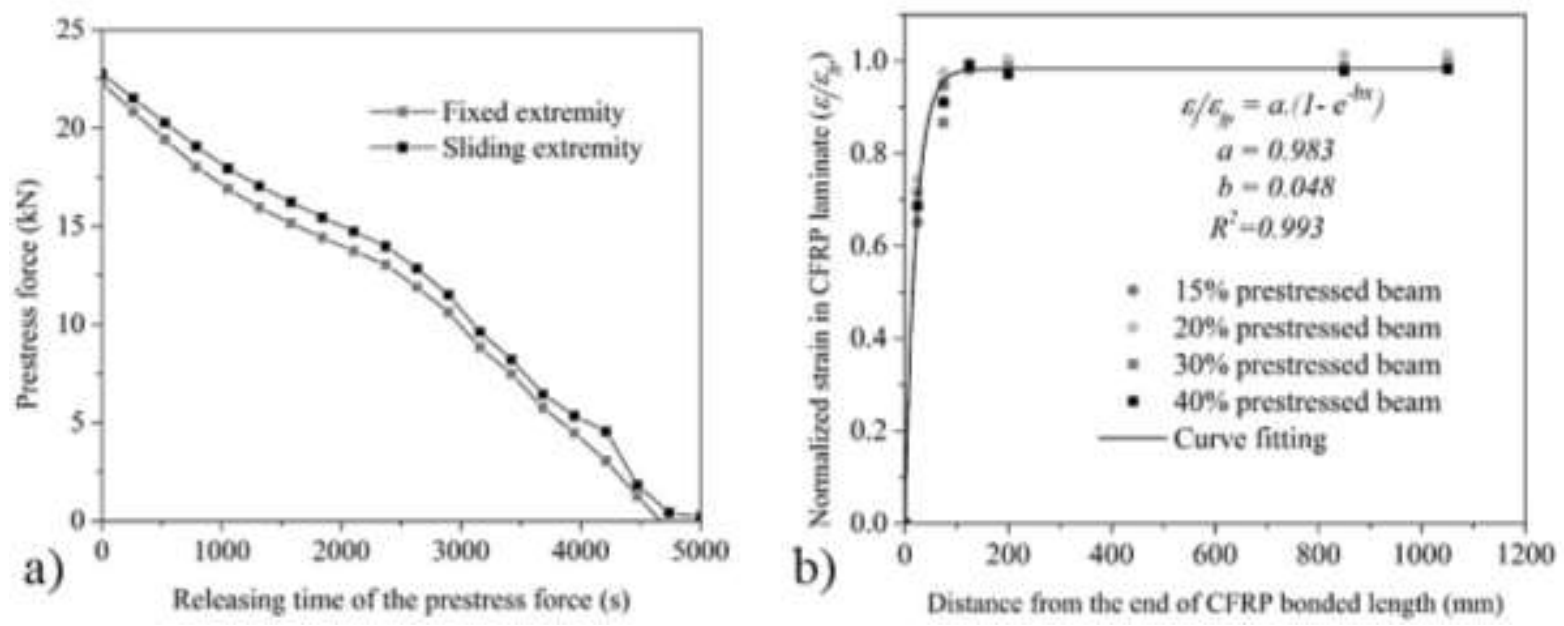

Figure 3: a) Release of the $40 \%$ prestress force at sliding and fixed extremities, b) tensile strain distribution along the CFRP bonded length 

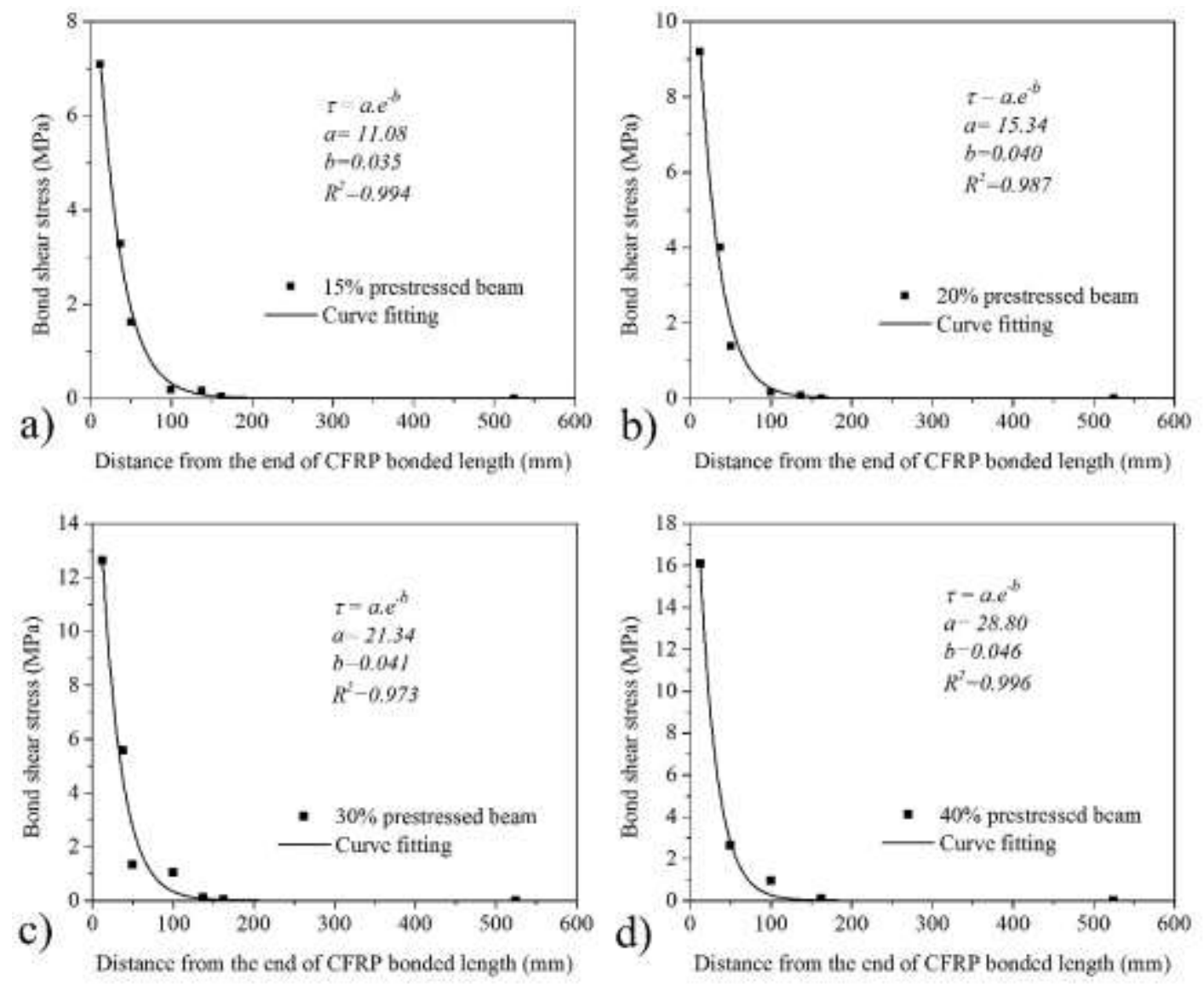

Figure 4: Bond shear stress distribution after the release of the prestress force for the prestress level of: a) $15 \%$, b) $20 \%$, c) $30 \%$, d) $40 \%$ 


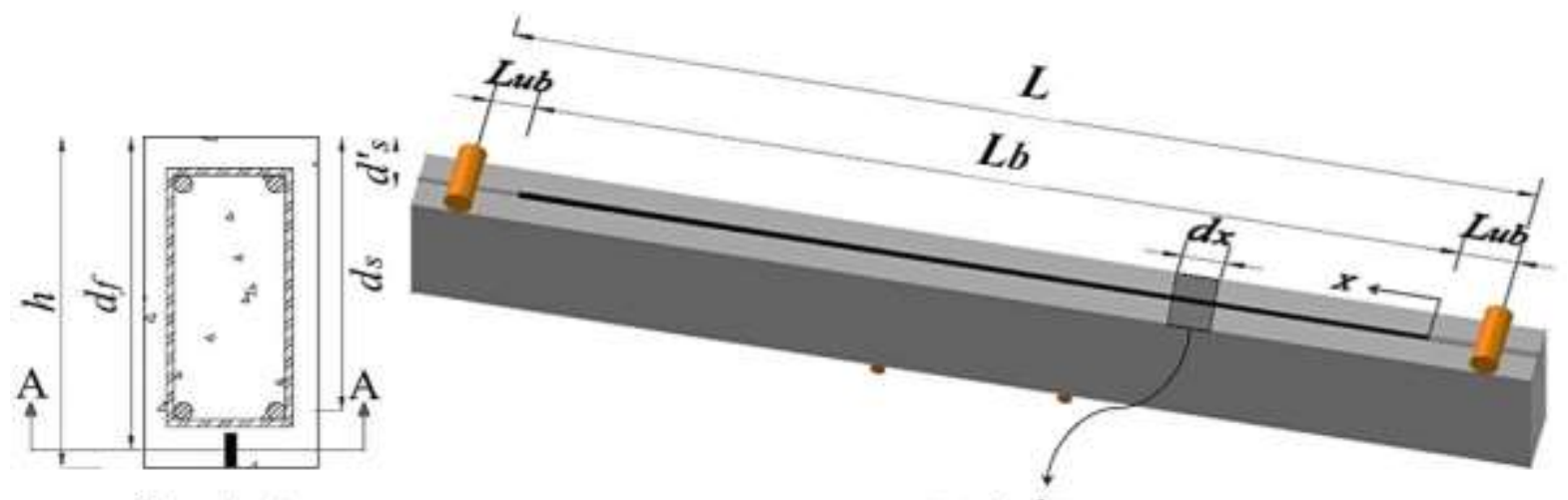

Sec. A-A:

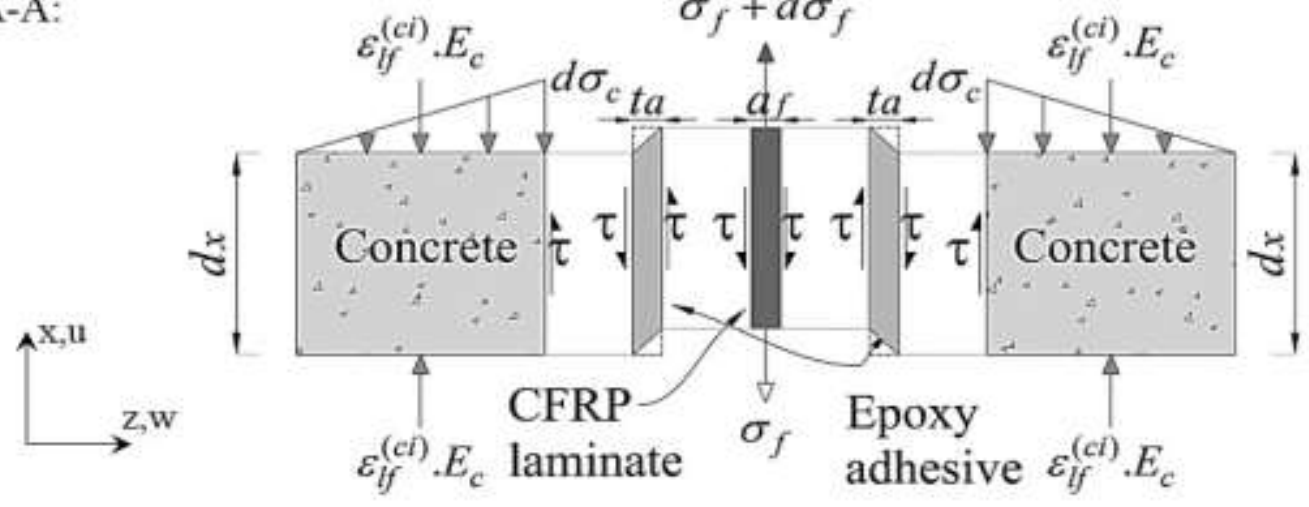

Figure 5: Infinitesimal portion of strengthened beam after releasing of prestress force 


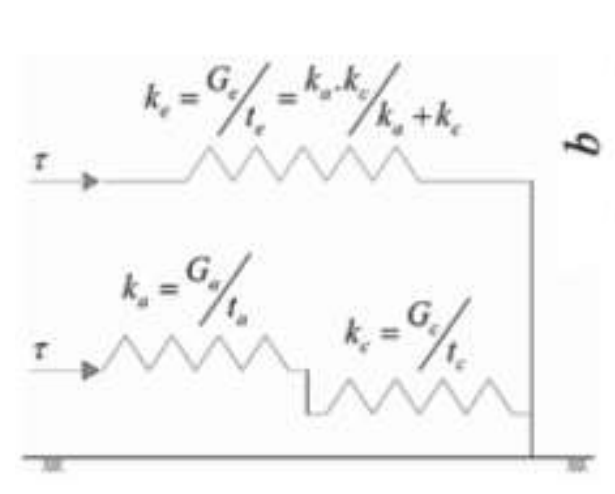

a)

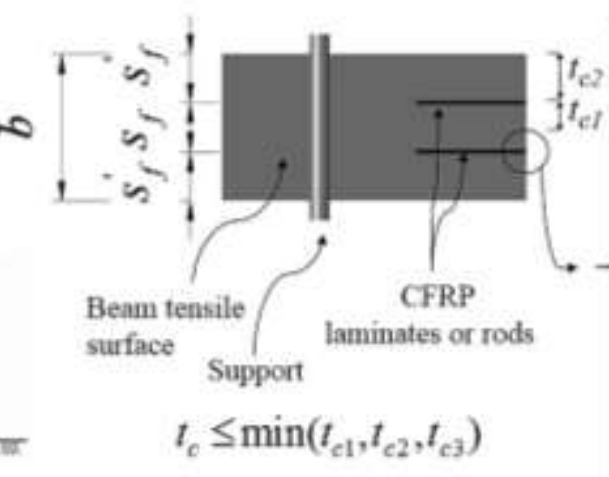

b)

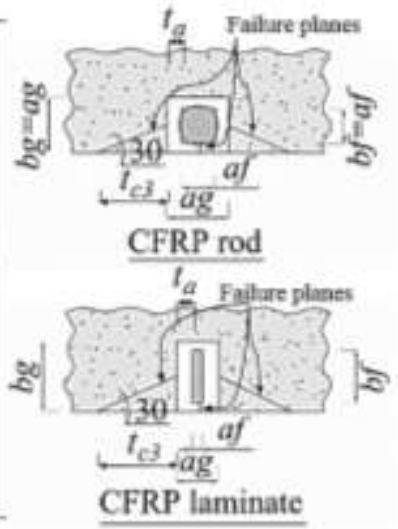

CFRP laminate

Figure 6: a) Schematic spring in series for bond shear stiffness, b) view of the bottom tensile surface of the beam in the zone of the extremities of the CFRP reinforcement 


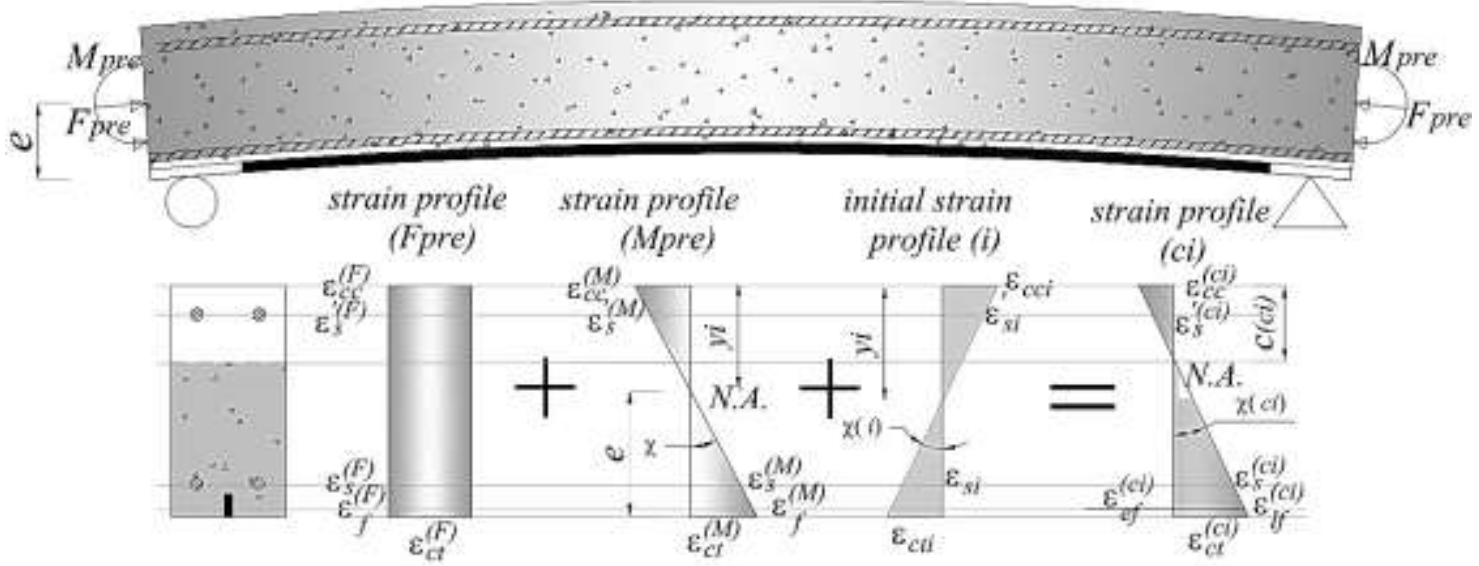

Figure 7: Strain profile of the prestressed strengthened beam due to initial negative camber 

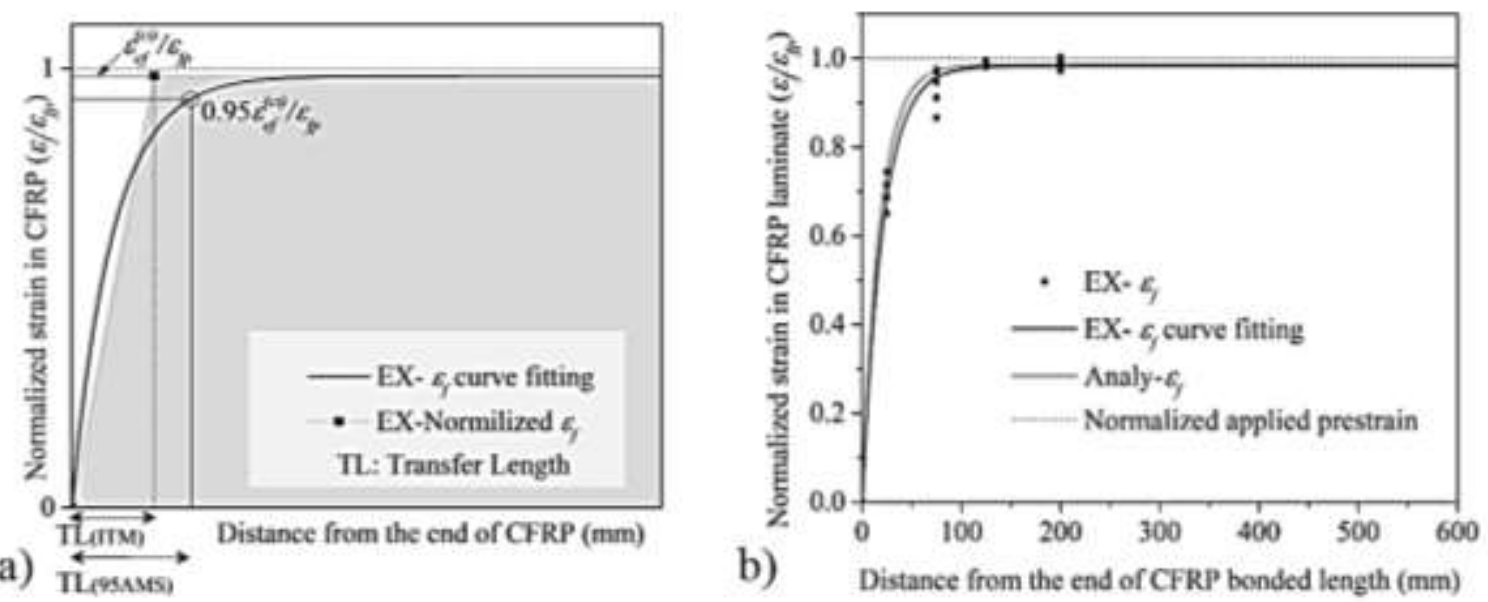

b) Distance from the end of CFRP bonded length ( $\mathrm{mm}$ )

Figure 8: a) Prestress transfer length according to 95\%AMS and ITM methods, b) analytical prediction of the tensile strain distribution in the CFRP reinforcement 

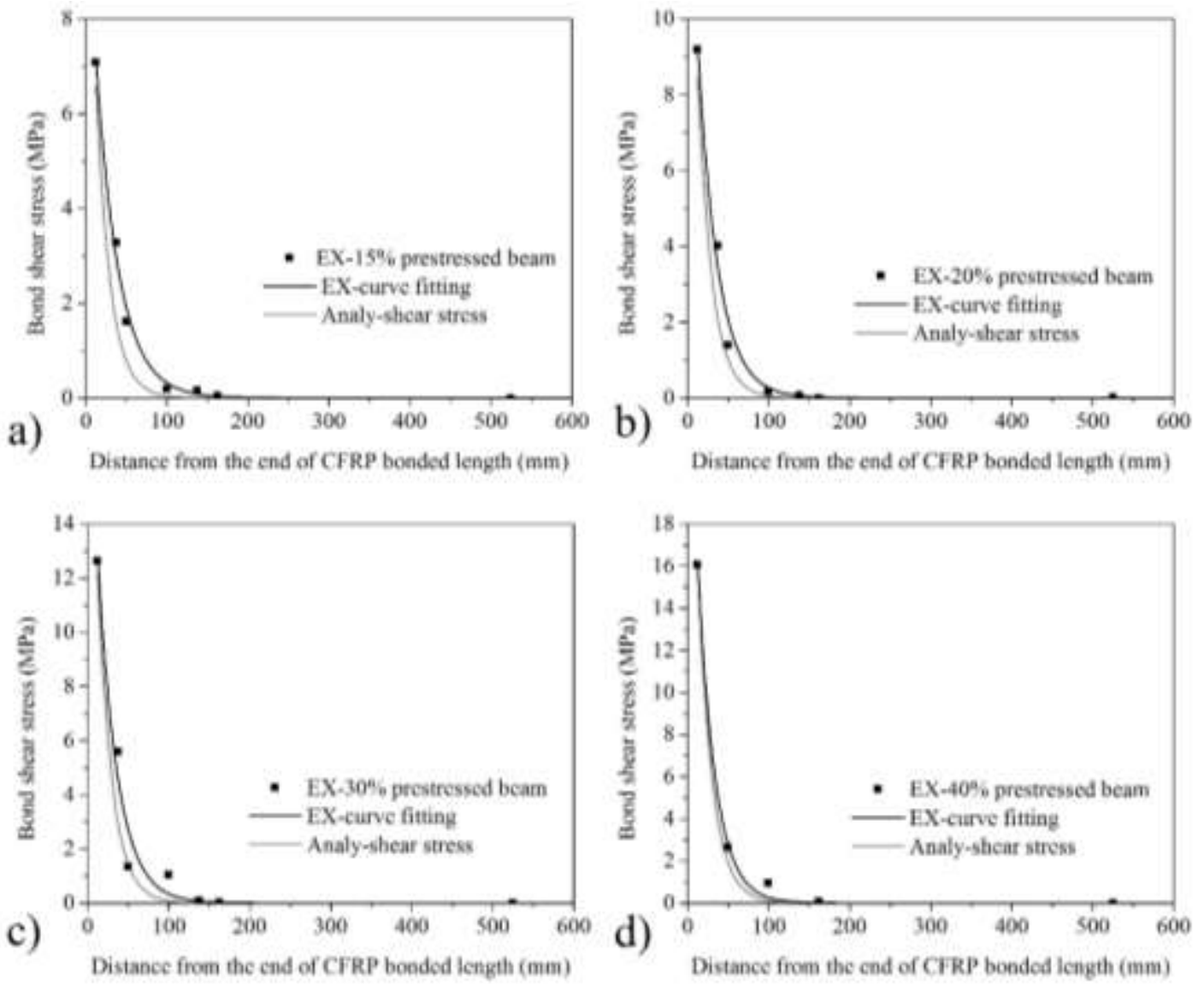

Figure 9: Analytical prediction of bond shear stress for the beam prestressed at the level of: a) $15 \%$, b) $20 \%$, c) $30 \%$, d) $40 \%$ 

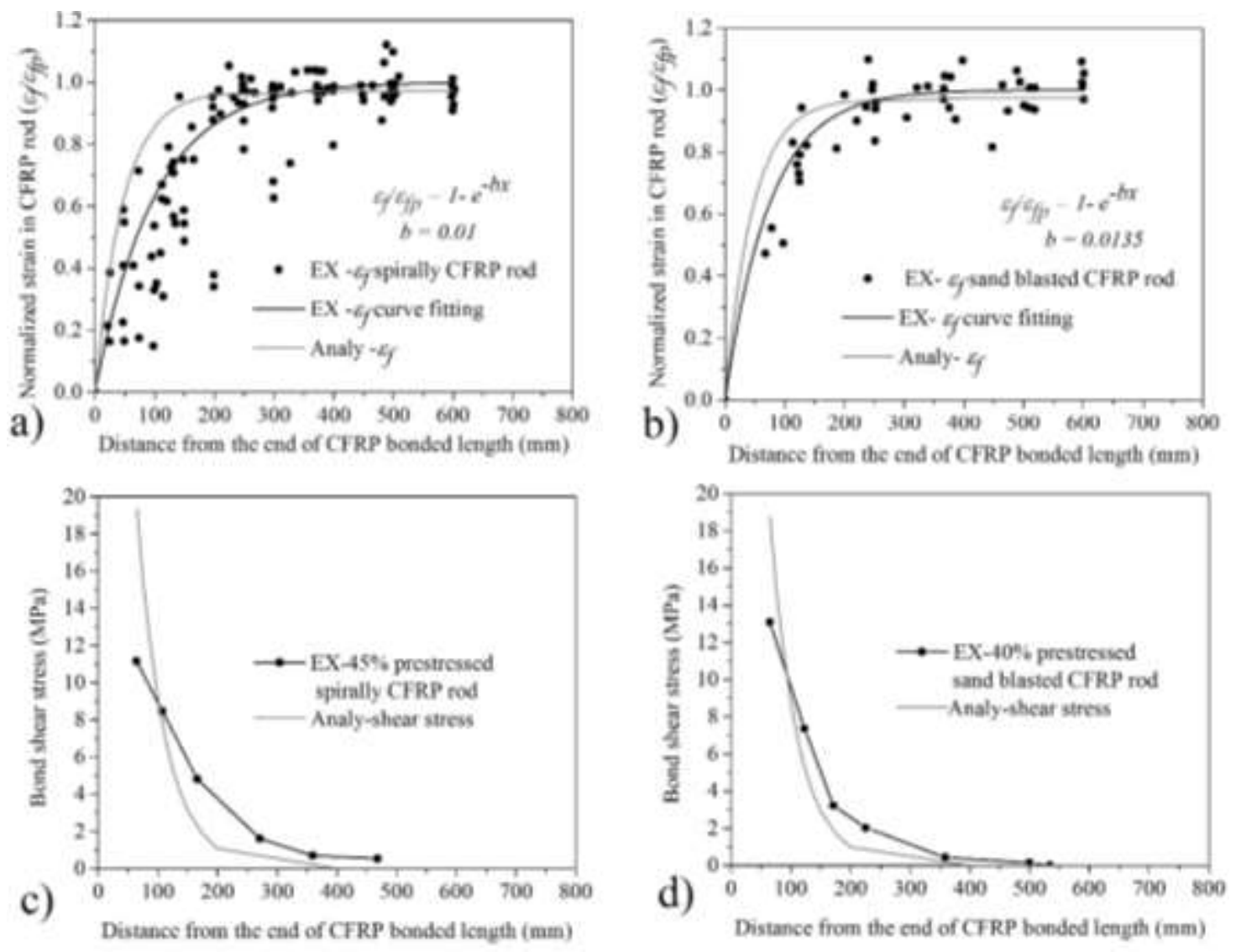

Figure 10: Analytical prediction of the tensile strain distribution of the CFRP reinforcement for: a) spirally CFRP, b) sand blasted CFRP, and bond shear stress for: c) $45 \%$ prestressed spirally CFRP, d) $40 \%$ prestressed sand blasted CFRP (Badawi et al. (2010)) 


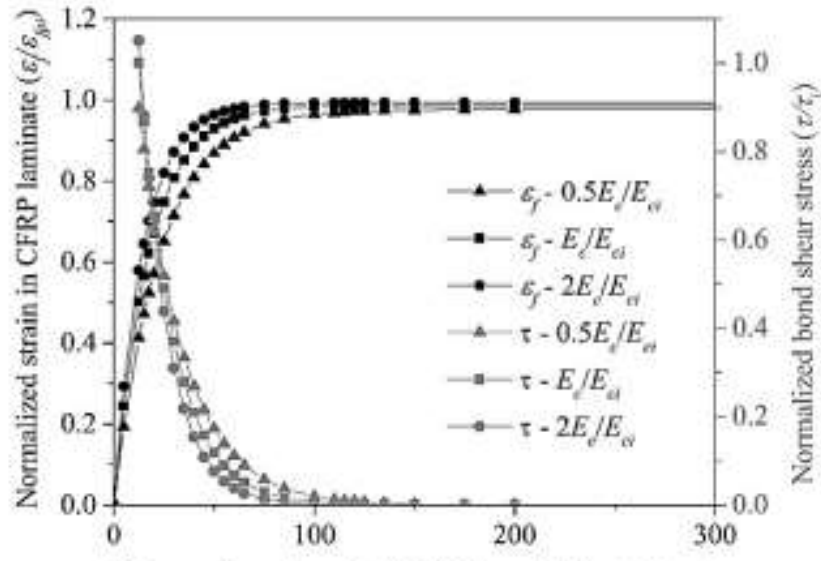

a)

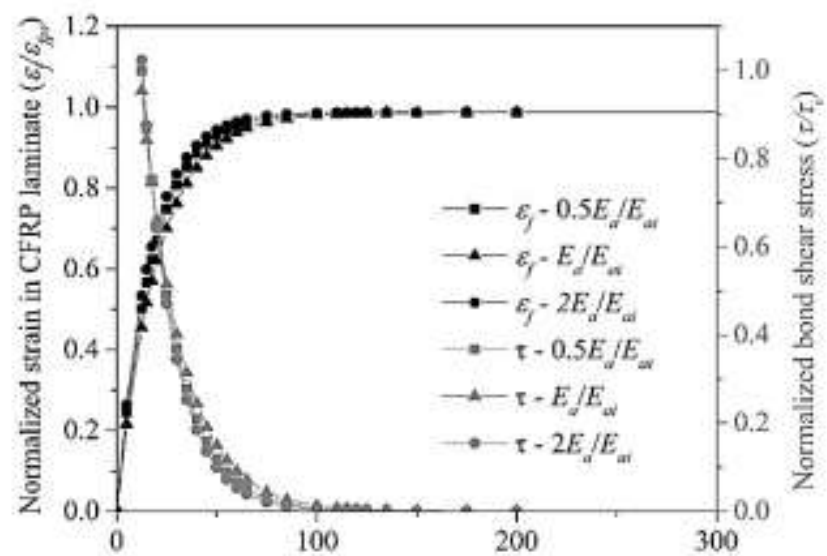

C) Distance from the end of CFRP bonded length ( $\mathrm{mm}$ )

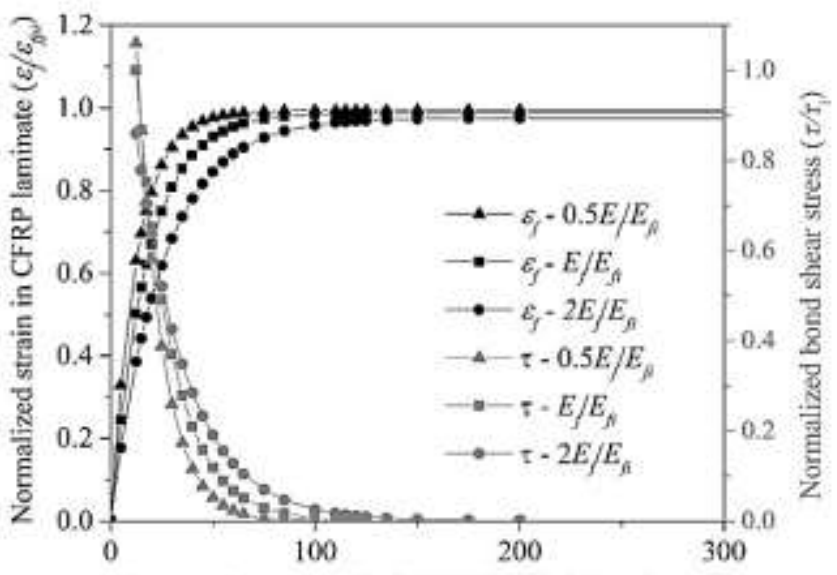

e) Distance from the end of CFRP bonded length (mm)

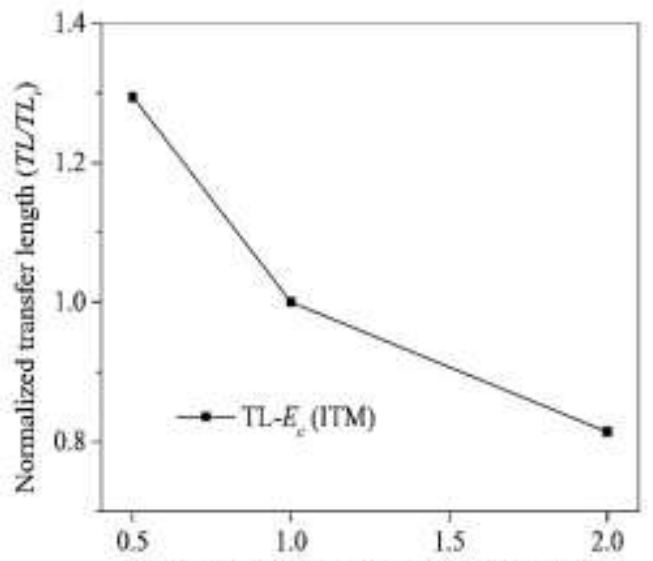

b)
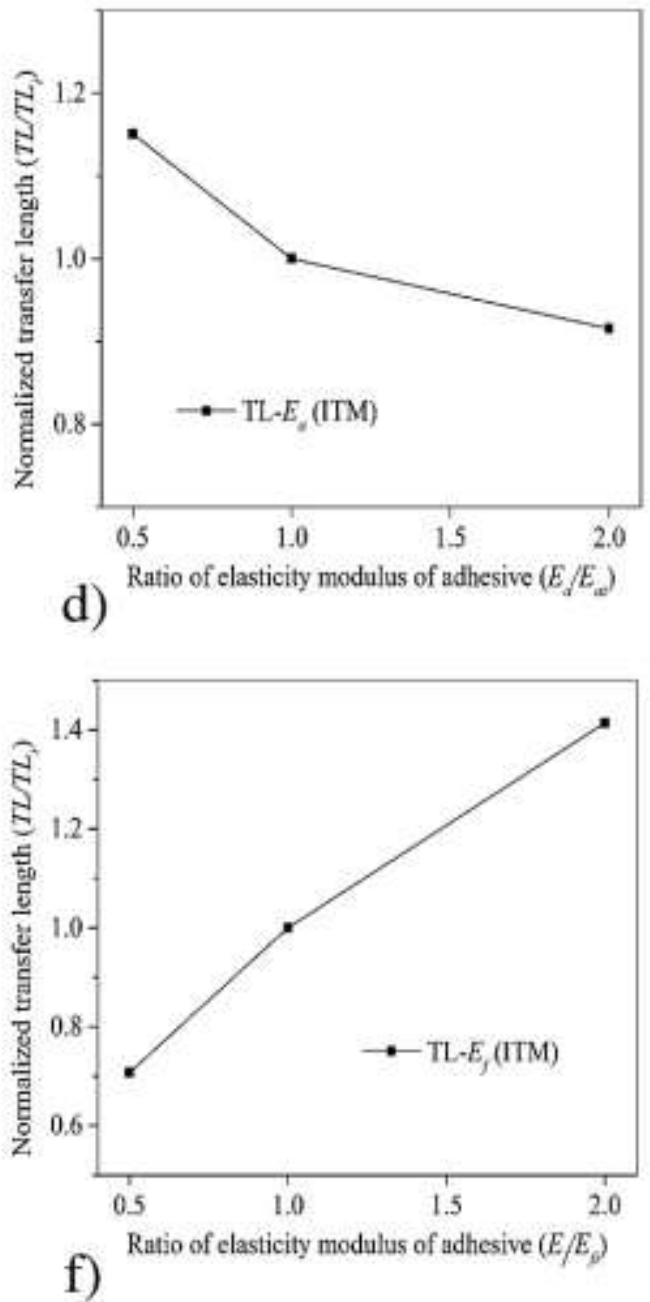

Figure 11: Influence of the: elasticity modulus of concrete on the: a) normalized CFRP tensile strain and bond shear stress, b) normalized prestress transfer length; elasticity modulus of adhesive on the: c) normalized CFRP tensile strain and bond shear stress, d) normalized prestress transfer length; elasticity modulus of CFRP on the: e) normalized CFRP tensile strain and bond shear stress, f) normalized prestress transfer length 


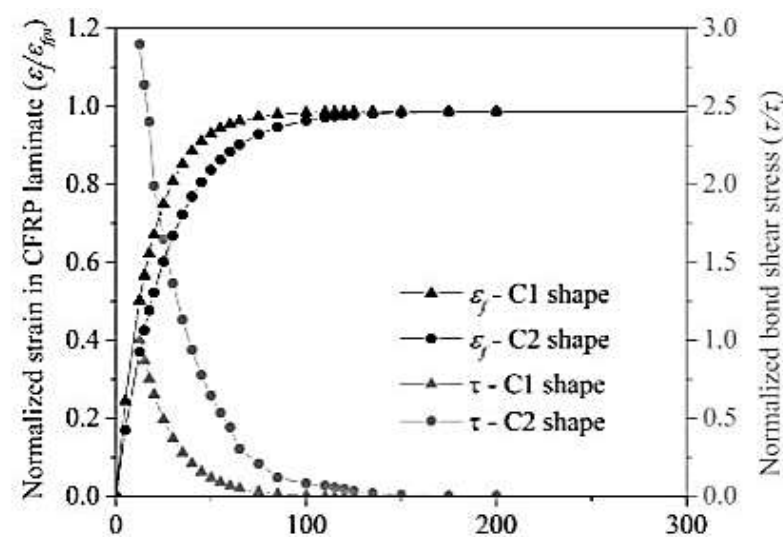

a)

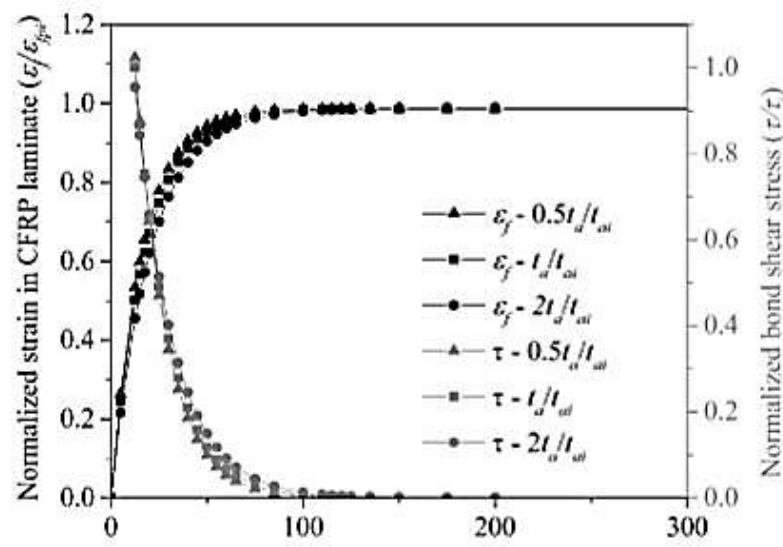

C) Distance from the end of CFRP bonded length ( $\mathrm{mm}$ )
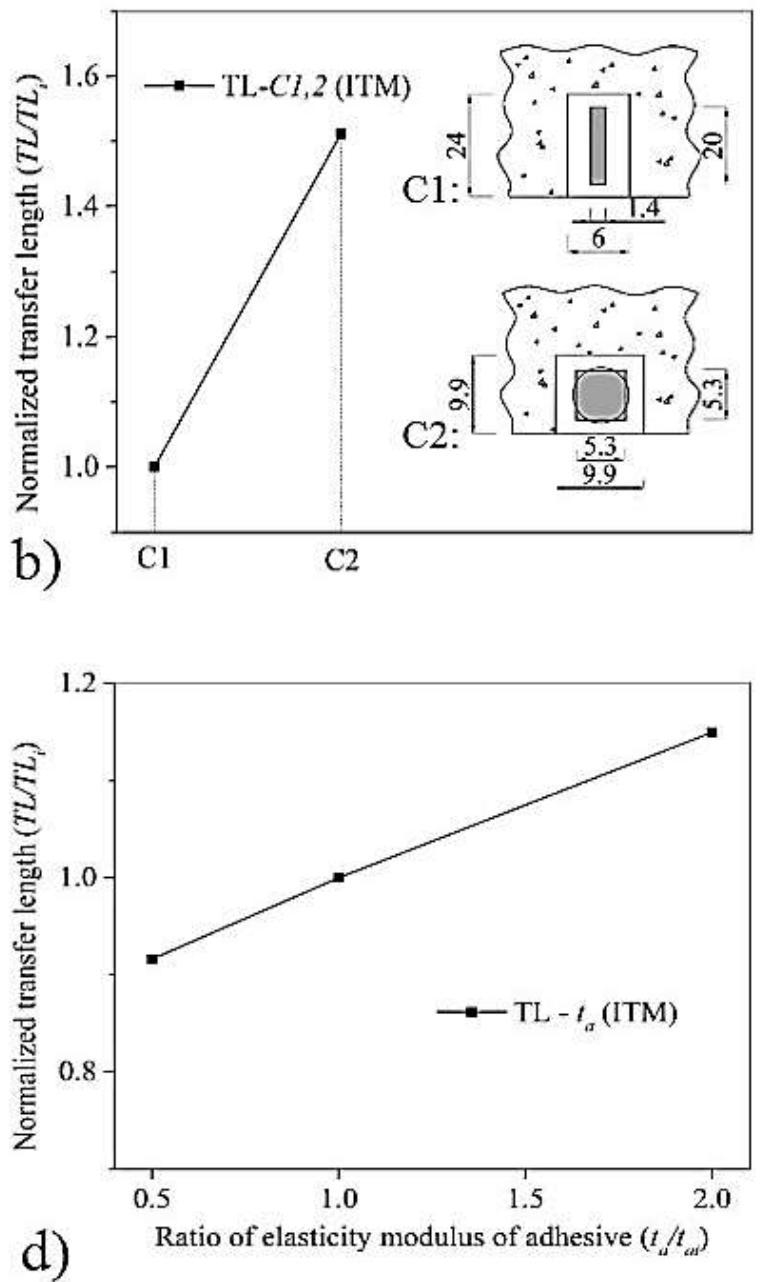

Figure 12: Influence of the geometry of the CFRP bar cross section on the: a) normalized CFRP tensile strain and bond shear stress, b) normalized prestress transfer length; influence of the thickness of adhesive layer on the: c) normalized CFRP tensile strain and bond shear stress, d) normalized prestress transfer length 

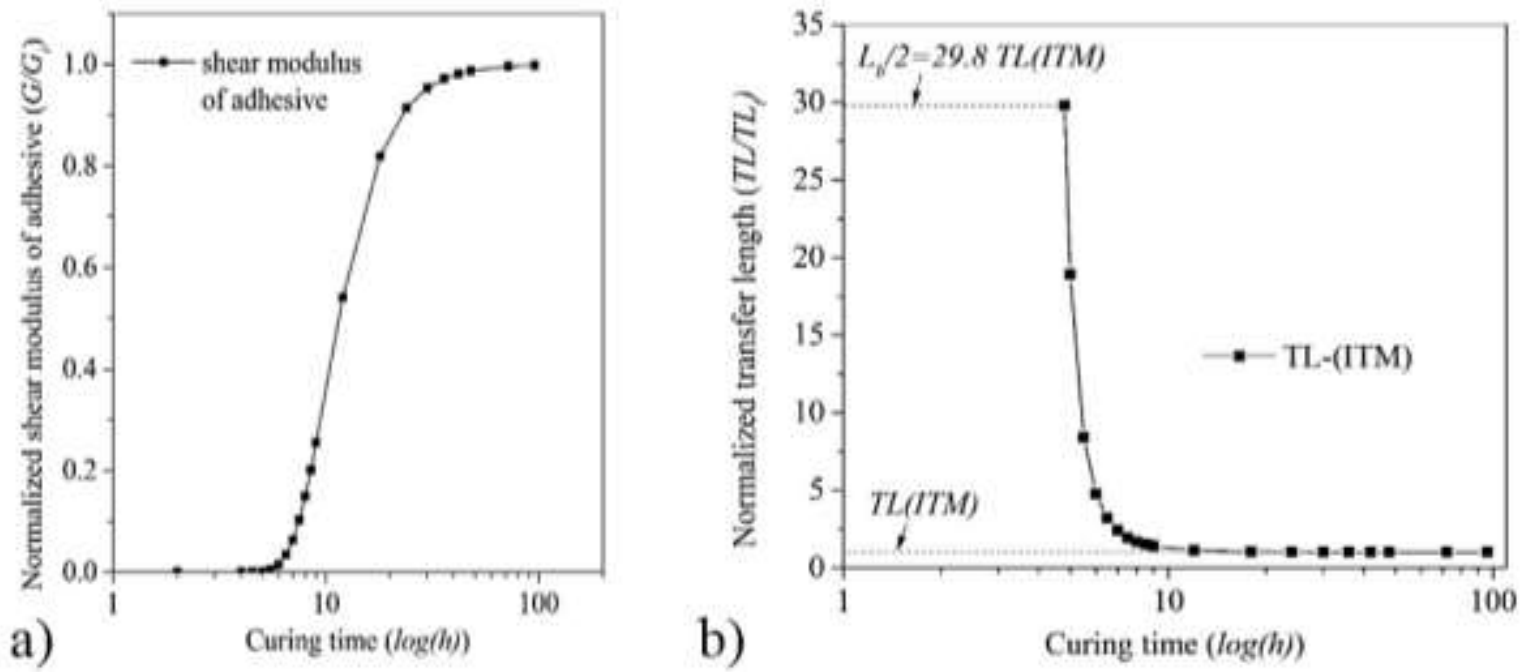

Figure 13: a) Shear modulus evolution of the epoxy adhesive during the curing time, b) prestress transfer length during the curing time 